\title{
Inhibition of cancer progression by a novel trans-stilbene derivative through disruption of microtubule dynamics, driving G2/M arrest, and p53-dependent apoptosis
}

\author{
Pravat Kumar Parida', Barun Mahata', Abhisek Santra', Sohini Chakraborty², Zhumur Ghosh², Sanghamitra Raha ${ }^{3}$, \\ Anup Kumar Misra ${ }^{1}$, Kaushik Biswas (10 ${ }^{1}$ and Kuladip Jana (10
}

\begin{abstract}
Resveratrol, a trans-stilbene polyphenolic compound and its synthetic analogs are widely used bioactive molecules due to their remarkable chemo-preventive potential. Here, we have identified a novel synthetic trans-stilbene compound, Z-DAN-11 ((Z)-3-(3, 4-dimethoxyphenyl)-2-(3, 4, 5-trimethoxyphenyl) acrylonitrile) which shows remarkable efficacy in blocking tumor growth and progression both in vitro and in vivo. Z-DAN-11 inhibits proliferation of cancer cells in vitro through microtubule depolymerization that induced G2/M arrest and consequently leads to apoptotic cell death. More importantly, Z-DAN-11 shows limited cytotoxicity to normal cells as compared to cancer cells. Quite interestingly, we have found that Z-DAN-11-mediated ROS production helps in dramatic alteration in the mitochondrial redox status which critically contributes to the apoptosis. Mechanistic studies reveal that Z-DAN-11 induces the expression of pro-apoptotic proteins and decreases anti-apoptotic protein expression that decisively helps in the activation of caspase 8, caspase 9, and caspase 3, leading to cleavage of PARP1 and cell death via intrinsic and extrinsic pathways of apoptosis. Moreover, Z-DAN-11-mediated apoptosis of cancer cells is through a partial p53dependent pathway, since both HCT116 p53 $3^{-1-}$ cells as well as p53-silenced cells (siRNA) were able to block apoptosis partially but significantly. Importantly, Z-DAN-11 also imparts its anti-tumorigenic effect by inhibiting clonogenic property and anchorage-independent growth potential of cancer cells at concentrations at least 10 times lower than that required for inducing apoptosis. Finally, in vivo study with immuno-competent syngeneic mice shows Z-DAN-11 to be able to impede tumor progression without any adverse side-effects. Hence, we identified a novel, synthetic trans-stilbene derivative with anti-tumorigenic potential which might tremendously help in devising potential therapeutic strategy against cancer.
\end{abstract}

\section{Introduction}

Among the various interventions used therapeutically against cancer, chemotherapy along with radiotherapy has

\footnotetext{
Correspondence: Kaushik Biswas (kbiswas_1@yahoo.com) or Kuladip Jana (kuladip_jana@yahoo.com) (kuladip.jana@gmail.com)

${ }^{1}$ Division of Molecular Medicine Bose Institute P1/12, C.IT. Scheme VIIM Kolkata West Bengal 700054 India

${ }^{2}$ The Bioinformatics Center, Bose Institute, Kolkata, West Bengal 700054, India Full list of author information is available at the end of the article Edited by $\mathrm{H}-\mathrm{U}$ Simon
}

been the most widely used and potential strategies for treating this disease $\mathrm{e}^{1,2}$. Although, an ideal chemotherapeutic drug should target a cancer cell by acting against a cancer-specific receptor, protein or DNA, in reality, however, chemotherapeutic applications are limited primarily owing to their adverse effects on the normal cells $^{3,4}$. This has increasingly led to studies aimed towards identification of novel compounds, preferably from natural sources having anti-cancer potential with minimal

\section{(c) The Author(s) 2018}

(c) (i) Open Access This article is licensed under a Creative Commons Attribution 4.0 International License, which permits use, sharing, adaptation, distribution and reproduction c. in any medium or format, as long as you give appropriate credit to the original author(s) and the source, provide a link to the Creative Commons license, and indicate if changes were made. The images or other third party material in this article are included in the article's Creative Commons license, unless indicated otherwise in a credit line to the material. If material is not included in the article's Creative Commons license and your intended use is not permitted by statutory regulation or exceeds the permitted use, you will need to obtain permission directly from the copyright holder. To view a copy of this license, visit http://creativecommons.org/licenses/by/4.0/. 
collateral damages to normal cells. Among them, polyphenols, many of which are found to be abundantly available in edible fruits, have shown promise ${ }^{5,6}$; however, only a few of these went past laboratory studies to being potentially therapeutic against cancer ${ }^{7}$. In recent years, trans-stilbene polyphenolic compounds like Resveratrol have gained tremendous attention due to their diversified biological effects ${ }^{8-10}$. Several methoxy and hydroxy derivatives of trans-stilbene have shown to possess anticancer activity in various human cancer cells through growth suppression by inducing cell cycle arrest and apoptosis ${ }^{11-13}$. Hence, the need to identify potential leads that can block cancer progression through targeted blocking of cells in particular phase of cell cycle ${ }^{14}$.

In the present study, we synthesized a number of trans-stilbene derivatives in an attempt to identify potential anti-cancer leads which is able to deliver a multi-modal yet targeted anti-cancer therapy, through affecting some of the key cellular processes primarily involved in carcinogenesis. Here, we evaluated the anticancer potential of 22 synthetic trans-stilbene derivatives using several cancer cell lines and identified one lead, Z-DAN-11 ((Z)-3-(3, 4-dimethoxyphenyl)-2-(3, 4, 5-trimethoxyphenyl) acrylonitrile), based on its ability to inhibit proliferation of cancer cells but not normal cells. Z-DAN-11 caused G2/M arrest in cancer cells, primarily by interfering with tubulin polymerization leading to disruption of microtubule formation. Furthermore, Z-DAN-11 was also able to induce genomic instability by DNA damage and consequent activation of p53 leading to activation of the caspase cascade eventually inducing apoptosis. In vivo, Z-DAN-11 demonstrates dose-dependent reduction in tumor burden and tumor progression in Balb/c mice without any significant hepatotoxicity. Hence, trans-stilbene derivative, Z-DAN-11 holds tremendous potential as an ideal lead towards targeted cancer chemotherapy, which either alone or in combination with existing chemotherapy may be used as a potential strategy towards cancer treatment.

\section{Results}

Synthesis and comparative cytotoxic efficacies of transstilbene derivatives

(Z)-2, 3-diarylacrylonitrile (trans-stilbene) derivatives were synthesized as described earlier ${ }^{8}$. Primarily, the series of compounds (Z-DAN-1 to Z-DAN-22) shown in Fig. S1 were assessed for their ability to block proliferation of HeLa, MCF-7 (cancer cells), and NKE cells (normal kidney epithelial cell). The anti-proliferative efficacies of the tested compounds in terms of $\mathrm{IC}_{50}$ were presented in Table S1, which showed three compounds Z-DAN-10, ZDAN-11, and Z-DAN-12 to possess higher efficacy in inhibiting proliferation of HeLa as well as MCF-7 cells compared to the other derivatives. However, Z-DAN-11 displayed the highest selectivity index (SI) in both MCF-7 $(\mathrm{SI}=7.26 \pm 0.43)$ and in HeLa $(8.08 \pm 0.58)$ cells over ZDAN-10 and Z-DAN-12. Thus, based on these results ZDAN-11 was selected as a potent anti-cancer lead.

\section{Z-DAN-11 demonstrates selective cytotoxicity against several cancer cell lines}

Based on its high SI, Z-DAN-11 was further tested in an array of cell lines including T47D, HBL-100, MDA-MB231, MDA-MB-468 (breast cancer cells), SK-RC-45 (renal carcinoma), HCT116 p53 ${ }^{\text {wt }}$, HCT116 $\mathrm{p} 53^{-/-}$cells (colon cancer), PC3 (prostate cancer), A549 (lung carcinoma) as well as WI-38 (lung fibroblast) cells as shown in Fig. 1a-c. Data shows differential yet significant cytotoxicity in most cancer cell lines, relative to the normal cells, NKE or WI38 (Fig. 1a-c). Interestingly, Z-DAN-11 showed limited cytotoxicity in HBL-100 $\left(\mathrm{IC}_{50}=32.67 \pm 12.54 \mu \mathrm{M}\right)$ and PC3 cells $(18.30 \pm 5.50 \mu \mathrm{M})$. Further dose-dependent increase in trypan blue positivity indicated significantly higher cytotoxic ability of Z-DAN-11 in MCF-7 and A549 cells, as compared to normal cells NKE or WI-38 (Fig. 1d, e), respectively. Notably, the cytotoxicity of Z-DAN-11 at higher concentrations $(5 \mu \mathrm{M}$ and $10 \mu \mathrm{M})$ was significantly higher in cancer cells, when compared to normal cells (Fig. 1d,e), indicating the selective ability of Z-DAN-11 to induce cancer cell death. Additionally, the photomicrographs confirmed the concentration-dependent increase in sensitivity of MCF-7 and A549 cells towards Z-DAN-11 as shown in Fig. 1f,g. Altogether these results provide strong evidence for Z-DAN-11 in possessing selective cytototoxicity towards cancer cells.

\section{Z-DAN-11 interferes with cell cycle progression by inducing $\mathrm{G} 2 / \mathrm{M}$ arrest}

Cycle distribution profile of various cancer cells in response to Z-DAN-11 clearly showed dose-dependent and time-dependent induction of G2/M arrest in both A549 (Fig. 2a,b) and MCF-7 cells (Fig. 2c,d). Interestingly, increase in the proportion of cells in G2/M phase was accompanied by decrease in cell population of G1 phase (Fig. 2a-d). Similar results were obtained in HeLa cells (Fig. S2a) however; MDA-MB-231 cells (Fig. S2b) showed significant but comparatively lower G2/M arrest. We also observed significant time-dependent increase in phospho-histone H3(Ser10) indicative of mitotic cells with condensed DNA ${ }^{15}$, in presence of $10 \mu \mathrm{M}$ of ZDAN-11 (Fig. 2e,f and Fig. S2c). However, MCF-7 and A549 cells showed relatively higher pH3-ser10-positive cells as compared to MDA-MB-231 which correlated with propidium iodide staining. Collectively these results suggest that Z-DAN-11 treatment induce G2/M arrest thereby playing a critical role in blocking cellular proliferation. 

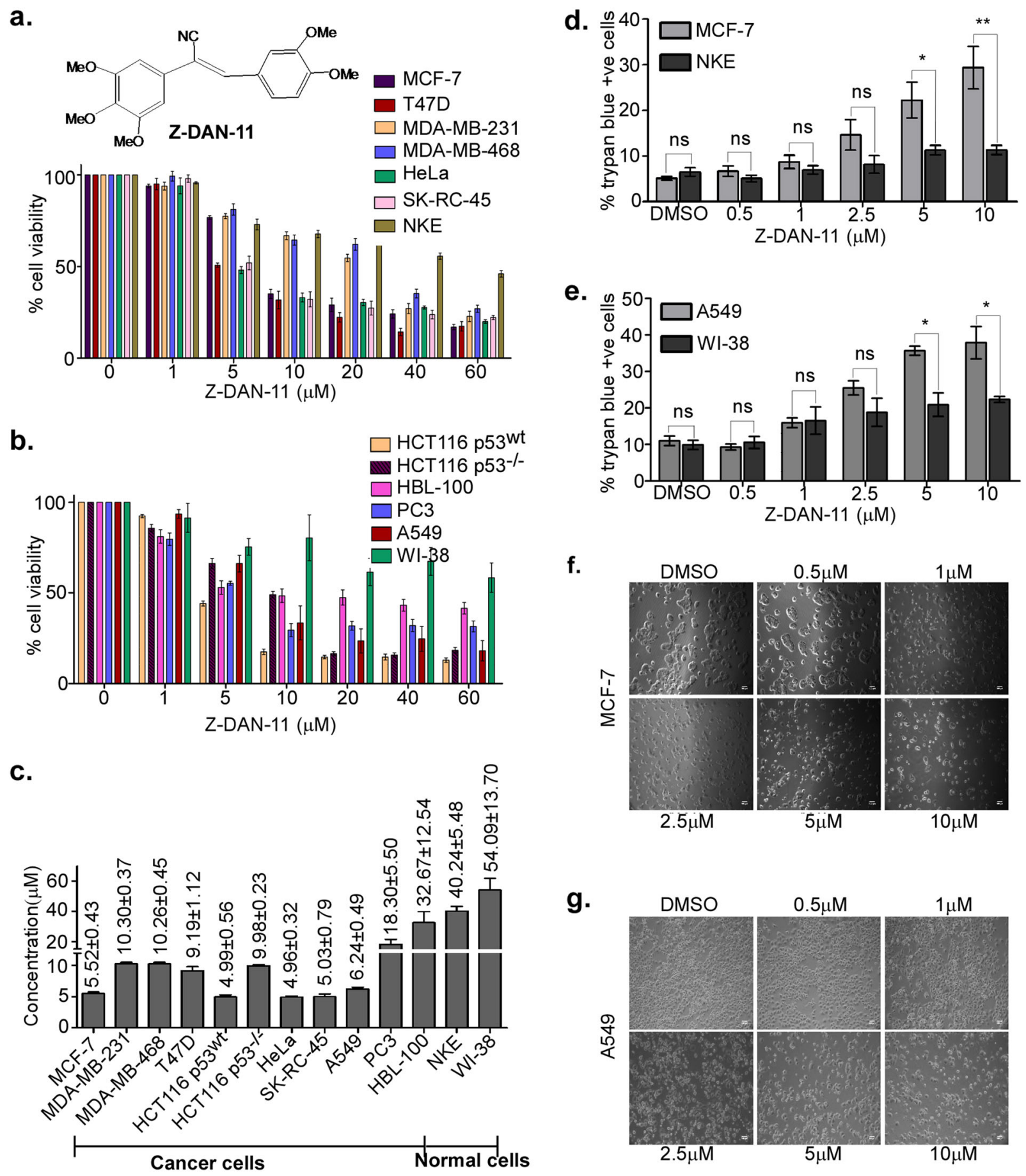

f.

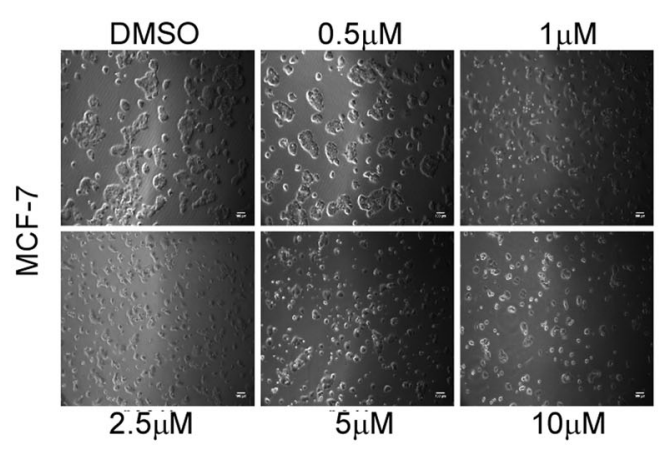

g.

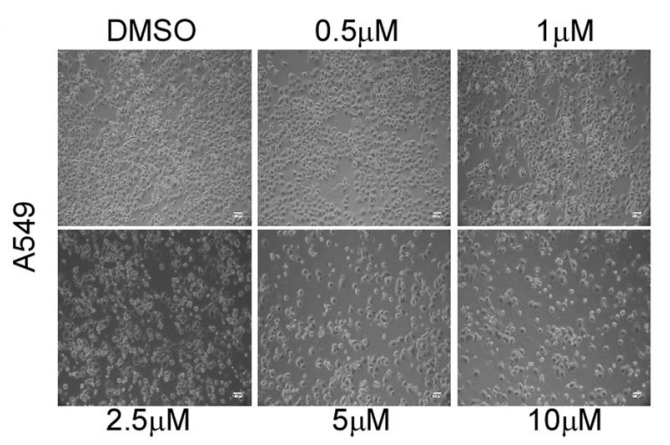

Fig. 1 Z-DAN-11 demonstrates selective cytotoxicity against several cancer cell lines. In vitro cytotoxicity was measured by MTT assay in presence of Z-DAN-11 (0-60 $\mu \mathrm{M})$ in various cell lines including a MCF-7, T47D, HeLa, SK-RC-45, MDA-MB-231, MDA-MB-468, NKE, and b HCT116 p53 ${ }^{\text {wt }}$, HCT1 16 p53 ${ }^{-1-}$, A549, HBL-100, PC3, and WI-38. c Bar graph showing comparative IC 50 values of Z-DAN-11 in various cancer cells (MCF-7, T47D, HeLa, SK-RC-45, MDA-MB-231, MDA-MB-468, HCT116 p53 ${ }^{\text {wt }}$, HCT116 p53--- A549, HBL-100, PC3) and normal cells (NKE, WI-38). d, e Dose-dependent increase in trypan blue positivity indicating significantly higher cytotoxic ability of the Z-DAN-11 in MCF-7 and A549 cells, as compared to normal cells NKE and WI-38 respectively. $\mathbf{f}, \mathbf{g}$ Photomicrographs showing dose-dependent (0-10 $\mu \mathrm{M})$ anti-proliferative effect of Z-DAN-11 in MCF-7 and A549 cells respectively. For all experiments, $0.2 \%$ DMSO served as vehicle control. All the data represent mean \pm SEM of minimum three independent experiments $\left({ }^{*} p<0.05^{* *} p<0.01,{ }^{* * *} p<0.001\right.$, ns not significant) 


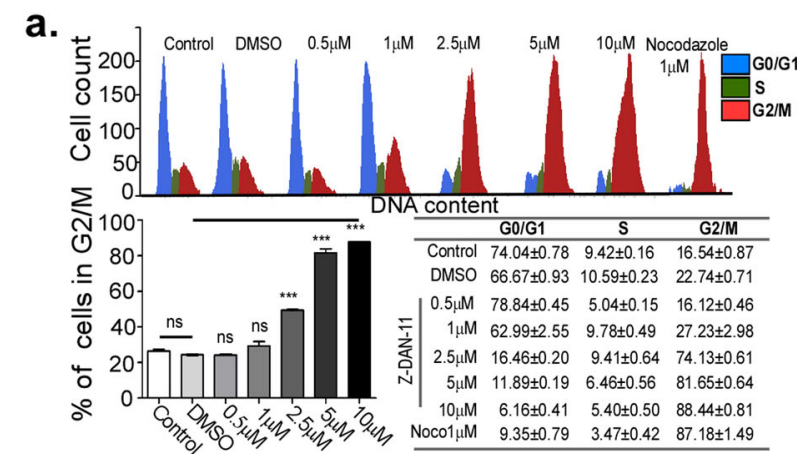

A549
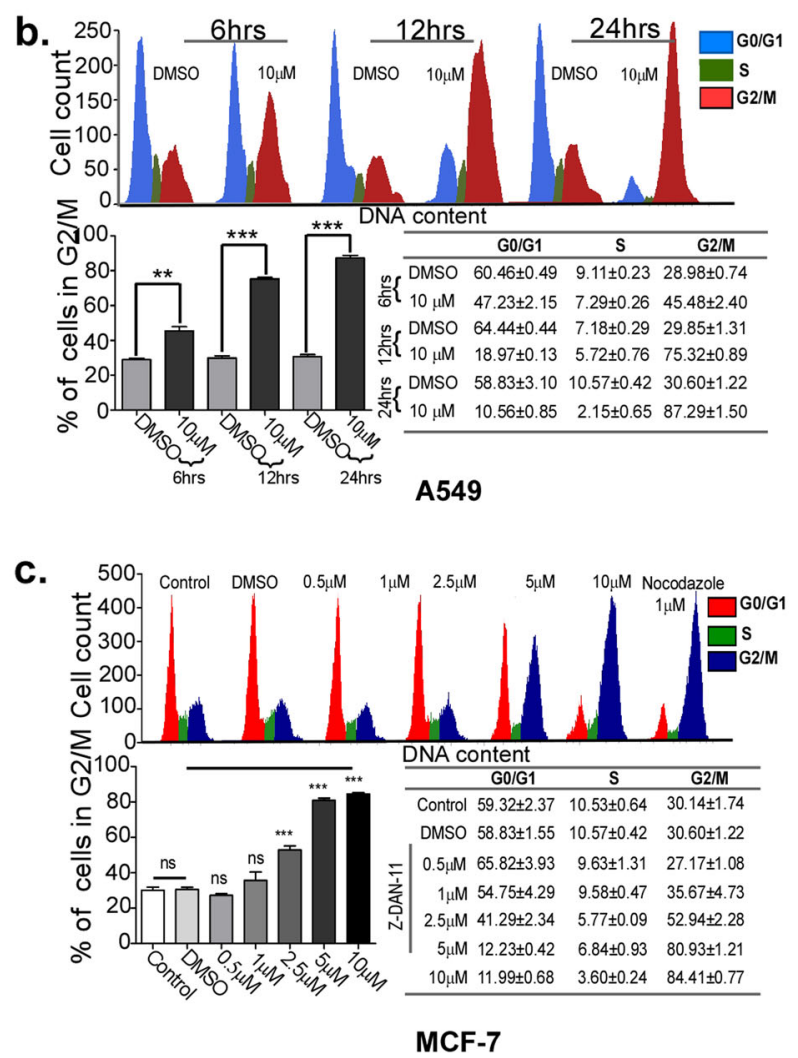
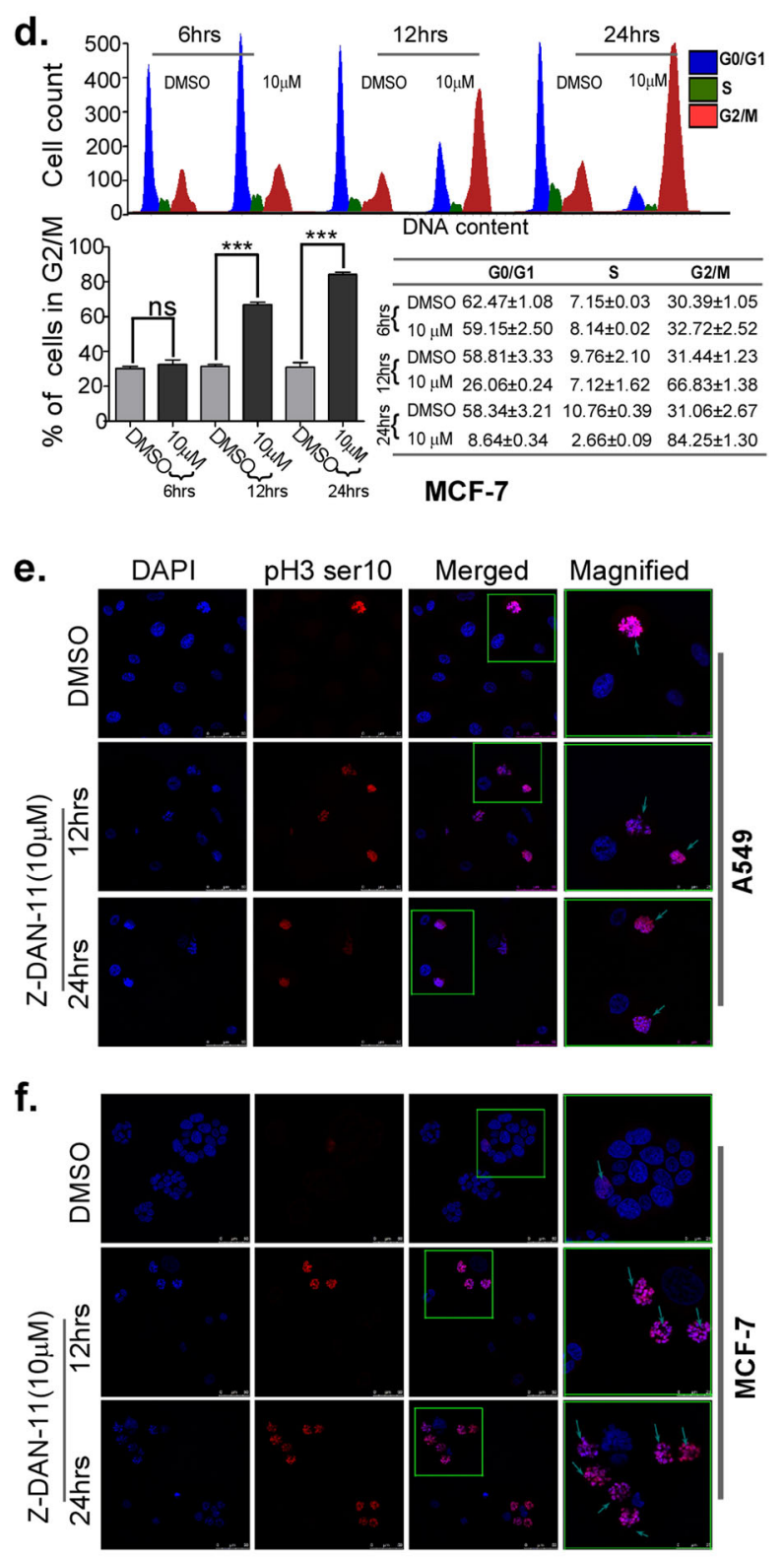

Fig. 2 Z-DAN-11 interferes with cell cycle progression by inducing G2/M arrest. Double thymidine blocked synchronized A549 and MCF-7 cells were treated with Z-DAN-11 in a dose-dependent $(0,0.5,1,2.5,5$, and $10 \mu \mathrm{M})$ as well as time-dependent $(6,12,24 \mathrm{~h})$ manner. Post treatment, cells were harvested and fixed with ethanol followed by PI staining to check cellular distribution in different phases of the cell by flow cytometry. Histograms representing dose-dependent and time-dependent increase in the proportion of A549 cells $\mathbf{a}, \mathbf{b}$ and MCF-7 cells $\mathbf{c}$, $\mathbf{d}$ in G2/M phase along with decrease in G1 phase in response to Z-DAN-11. One-way ANOVA followed by Dunnett's $t$-test was performed to comparisons of multiple group means (treatments) versus DMSO control. Data are representative of at least three independent experiments and bar graph shows mean \pm SEM ${ }^{*} p<0.05^{* *} p<0.01,{ }^{* * *} p<0.001$, ns not significant). Effect of Z-DAN-11 on mitotic DNA condensation marker $\mathrm{p}-\mathrm{H} 3$ ser10 proteins in e A549 and f MCF-7 cells. Here, cells were incubated with Z-DAN-11 (10 $\mu \mathrm{M})$ for the indicated time points and fixed with $3.7 \%$ formaldehyde. Post fixation cells were permeabilized with triton-X and incubated with anti-p-H3 ser10 primary antibody followed by incubation with Alexa-Fluor 594-conjugated secondary antibody. Counter staining was done using DAPI to visualize the nuclei. Images were acquired in Leica confocal microscope (Magnification: $\times 40)$

Z-DAN-11 induces differential expression of distinct gene sets involved in cell cycle and cell death-related processes

In order to observe the systemic impact of Z-DAN-11 treatment in gene expression, we did transcriptome analysis of Z-DAN-11 treated MCF-7 cells at 6 and $12 \mathrm{~h}$, along with untreated and DMSO treated cells using microarray. Comparative analysis revealed that Z-DAN11 treatment led to time-dependent increase in the 

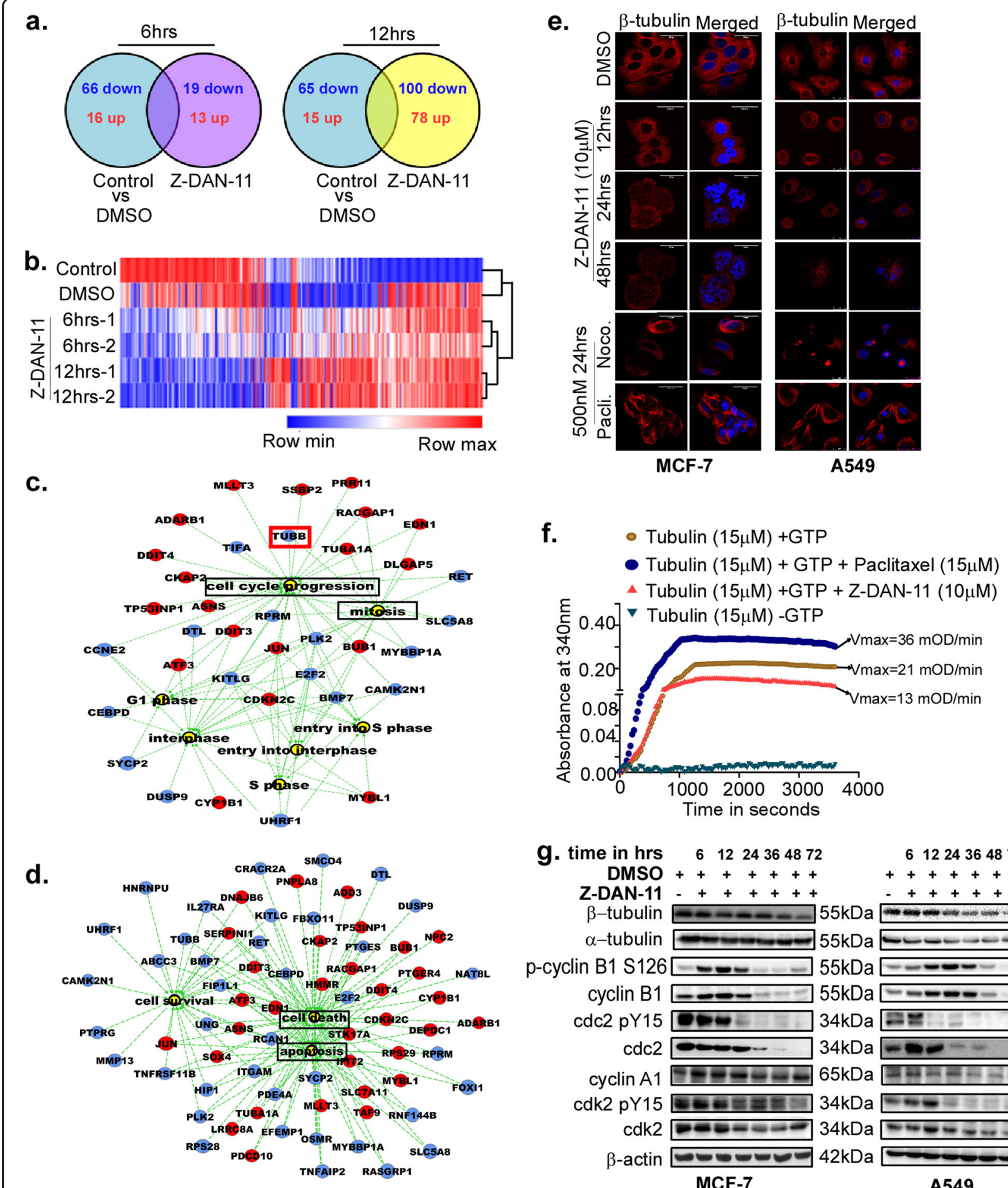
g. time in hrs $\quad 6 \quad 12 \quad 24364872$
61224364872
DMSO +++++++
$++++++$
Z-DAN-11 - + + + ++ +
$+++++$
$\beta$-tubulin $-\infty-\infty \mathrm{kDa}-\infty-\infty+\cdots$
$\alpha$-tubulin $-\infty \mathrm{kDa}$
p-cyclin B1 S126 -
cyclin B1 - 55ka
cdc2 pY15 DO- 34kDa 믈
cdc2 34kDa - s- -

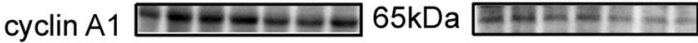

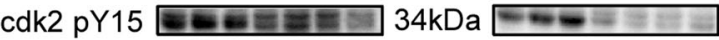

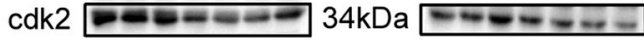
$\beta$-actin 42kDa
MCF-7
A549

Fig. 3 (See legend on next page.)

number of differentially regulated genes (DRGs), however the overall numbers of DRGs were highest at $12 \mathrm{~h}$ (Fig. 3a). Hierarchical clustering of the cell samples based on their gene expression, along with a heat map, demonstrate a distinct differential gene expression signature among the Z-DAN-11 treated and control samples 


\begin{abstract}
(see figure on previous page)
Fig. 3 Z-DAN-11 induces differential expression of distinct gene sets involved in cell cycle and cell death-related processes. a Microarray analysis representing differentially regulated genes (DRGs) in Z-DAN-11 treated MCF-7 cells at 6 and $12 \mathrm{~h}$ compared to DMSO control and untreated cells $(p \leq 0.05, F C \geq 2)$. b Heat map showing distinct contrast in gene expression between the Z-DAN-11 treated and the control samples. Gene interaction network involving DRGs specific to Z-DAN-11 treated cells at $12 \mathrm{~h}$ time point and involved in $\mathbf{c}$ cell cycle and $\mathbf{d}$ cell death-related functions. Upregulated genes are marked in red, downregulated genes are marked in blue and functions are marked in yellow. e Photomicrographs showing time-dependent decrease in $\beta$-tubulin in MCF-7 and A549 cells in response to Z-DAN-11 treatment. Briefly, cells were treated with Z-DAN-11 $(10 \mu \mathrm{M})$ for the indicated time points and fixed with 3.7\% formaldehyde. Post fixation cells were permeabilized with triton-X and incubated with $\beta$ tubulin antibody. Alexa-Fluor 594-conjugated secondary antibody was used followed by counter staining with DAPI. Finally, images were acquired in Leica confocal microscope (magnification: $\times 63$ ). $\mathbf{f}$ Effect of Z-DAN-11 on in vitro tubulin polymerization. Purified porcine tubulin was incubated with or without Z-DAN-11 or paclitaxel in tubulin polymerization buffer and kinetic loop study was carried out. $\mathbf{g}$ Western immunoblot data depicts ZDAN-11-mediated alternation in the expression of cell cycle-related proteins including a-tubulin and $\beta$-tubulin, cyclin A1, cyclin B1, phospho-cyclin B1 (S126), cdc2, phospho-cdc2 (Tyr15), cdk2, and phospho-cdk2 (Tyr15) in MCF-7 (left panel) and A549 cells (right panel)
\end{abstract}

(Fig. 3b). Functional enrichment analysis of the DRGs specific to the Z-DAN-11 treated cancer cells using IPA showed significant association of these genes (Tubb, Tuba, c-Jun, Tp53, Ddit3, Tgfbi etc.) in cell cycle and cell death-related processes (Fig. 3c,d), corroborating with our experimental validations (Fig. S3a-b).

\section{Z-DAN-11-mediated disruption of micro-tubular dynamics leads to G2/M cell cycle arrest}

Microarray data revealed altered expression of several genes involved in cell cycle regulation as well as cell death-related processes in response to Z-DAN-11 in MCF-7 cells, including but not limited to $\beta$-tubulin, which were validated by q-PCR (Fig. S3a-b). Both microarray as well as RT-PCR demonstrated comparable fold changes in the expression of these genes (Fig. S3b). Our western immunoblot and immunofluorescence data showed reduced expression of $\beta$-tubulin (Fig. 3e,g) but not $\alpha$ tubulin (Fig. 3g and Fig. S2d), which play critical role during the M-phase of cell division process ${ }^{16}$. We observed microtubule networks in DMSO as well as paclitaxel (a drug known to stabilize tubulin polymers ${ }^{17,18}$ ) treated condition in MCF-7 and A549 cells. On the contrary, there was a time-dependent decrease in the expression of $\beta$-tubulin indicative of disrupted microtubule networks in Z-DAN-11 $(10 \mu \mathrm{M})$ treated cells similar to those treated with the drug, nocodazole ${ }^{19}$ (Fig. 3e). Similar results were obtained with MDA-MB231 cells (Fig. S2e). Further, confirmation of tubulin depolymerization by Z-DAN-11 was obtained from kinetic loop experiment with purified porcine tubulin, which shows that Z-DAN-11-mediated $\left(V_{\max }=13 \mathrm{mOD} /\right.$ min) tubulin polymerization was comparatively lower than the control condition $\left(V_{\max }=21 \mathrm{mOD} / \mathrm{min}\right)$ while with paclitaxel $\left(V_{\max }=36 \mathrm{mOD} / \mathrm{min}\right.$.), polymerization efficiency was much higher (Fig. 3f). These results indicate that Z-DAN-11 interferes with microtubule polymerization process which leads to $\mathrm{G} 2 / \mathrm{M}$ arrest. Interestingly Schneider et al. discussed inhibition of tubulin polymerization for other Resveratrol derivative which is structurally different from Z-DAN-11 but alike Z-DAN11 it causes G2/M arrest through inhibition of tubulin polymerization $^{20}$. Moreover, western blot analysis of critical cell cycle regulatory proteins (Fig. 3g) show significant time-dependent decrease in the expression level of total Cdc2 along with phospho-cdc2 (Tyr15) in response to Z-DAN-11 treatment in both MCF-7 (Fig. 3g, left panel) and A549 cells (Fig. 3g, right panel). While cyclin B1 expression level initially increased up to $24 \mathrm{~h}$, significant decrease in cyclin B1 levels were observed post $36 \mathrm{~h}$ treatment with the compound (Fig. 3g). Phosphocyclin B1 (S126) also followed quite similar expression pattern as cyclin B1 both in MCF-7 and A549 cells. Cdk2 and phospho-cdk2 expression also showed a timedependent decrease in response to Z-DAN-11 treatment, with decrease mostly evident at late time points. Again, while Z-DAN-11 treatment did not affect the expression of cyclin A1 in MCF-7, time-dependent decrease in cyclin A1 was observed in A549 after $36 \mathrm{~h}$ (Fig. 3g).

\section{Z-DAN-11 treatment induces DNA fragmentation, ROS- mediated mitochondrial permeability transition, and apoptosis in human cancer cells}

Forty-eight hours post treatment with different concentrations of Z-DAN-11 $(0-10 \mu \mathrm{M})$ showed dosedependent induction of apoptosis in MCF-7, A549 as well as MDA-MB-231 cells, as indicated by the increased percentage of annexin V-FITC+ve cells (Fig. 4a,b and Fig. S4a). While the minimal concentration required for significant induction of apoptosis by Z-DAN-11 in MCF-7 and A549 cells (Fig. 4a,b) was $2.5 \mu \mathrm{M}$, in MDA-MB-231 cells (Fig. S4a) it was around $5 \mu \mathrm{M}$. Apoptosis induction in response to Z-DAN-11 was followed microscopically by transferase dUTP nick end labeling (TUNEL) assay ${ }^{21}$. Time-dependent increase in TUNEL-positive cells were observed in MCF-7, A549 (Fig. 4c) as well as MDA-MB231 cells (Fig. S4b) in response to Z-DAN-11. DAPI 


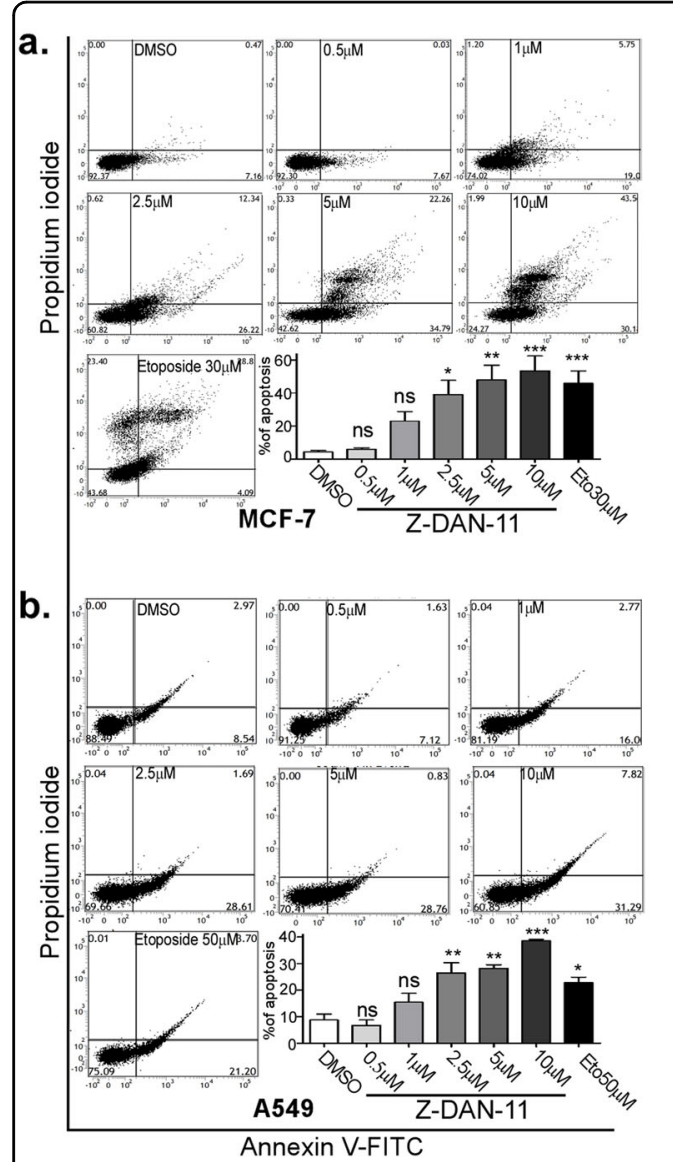

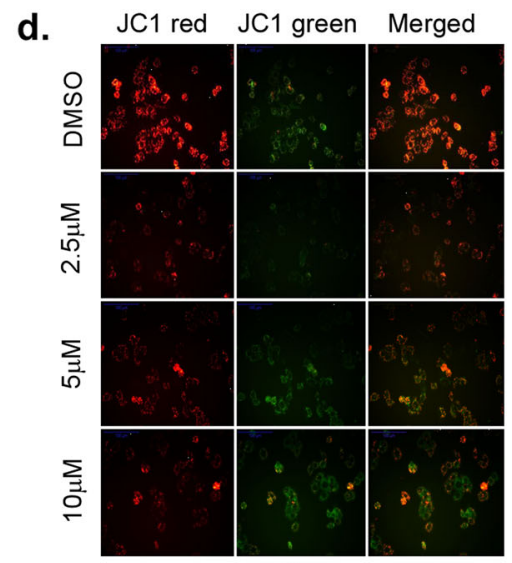

6hrs

๑.

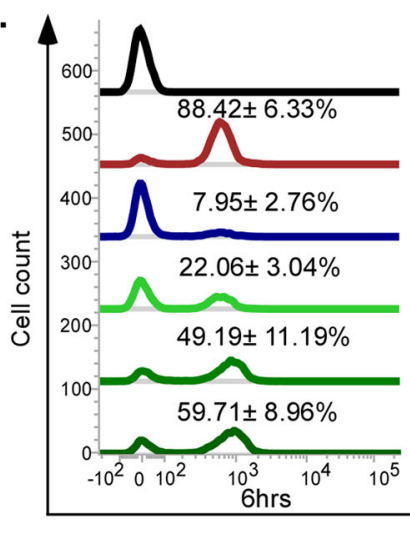

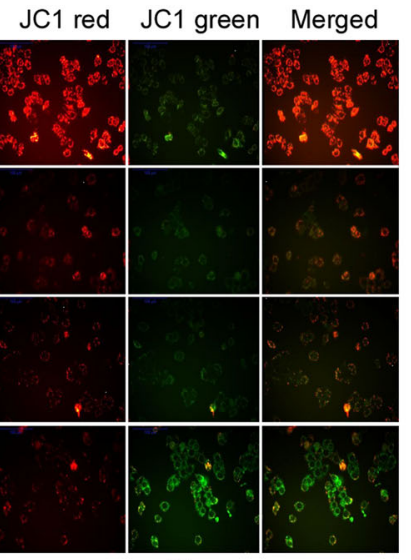

9hrs
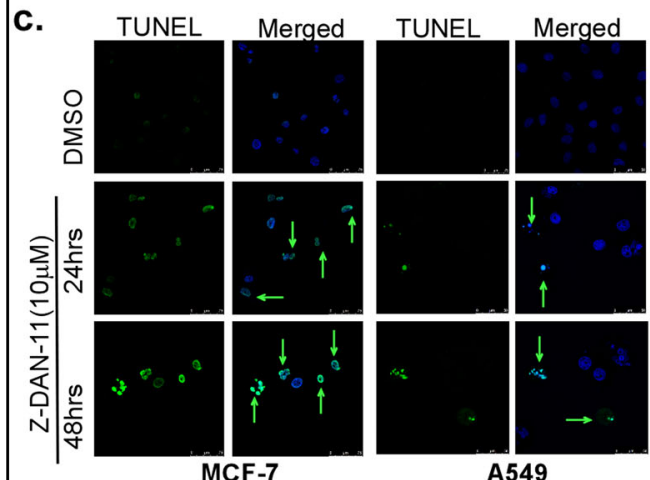

MCF-7

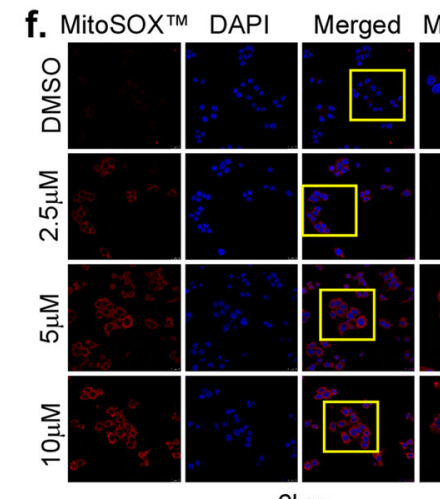

6hrs

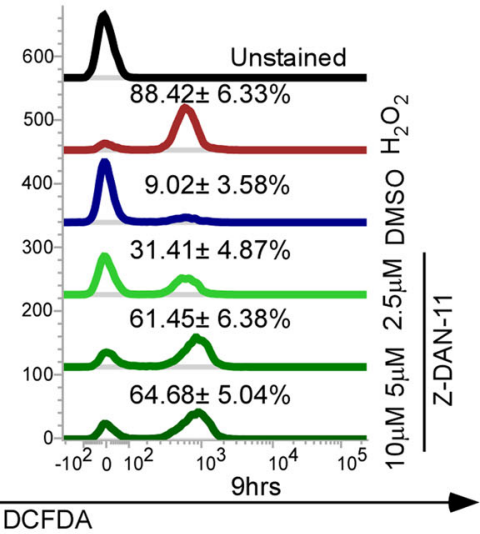

DCFDA

Fig. 4 Z-DAN-11 treatment induces DNA fragmentation, ROS mediated mitochondrial permeability transition (MPT) and apoptosis in human cancer cells. a, b Concentration-dependent increase in annexin V-FITC/PI-positive population of MCF-7 and A549 cells, respectively, in response Z-DAN-11 treatment. Post treatment with Z-DAN-11(0-10 $\mu \mathrm{M})$ for $48 \mathrm{~h}$, cells were stained with annexin V-FITC/PI and analyzed in FACs. c Identification of apoptotic nuclei by TUNEL staining showing time-dependent increase in TUNEL positivity in MCF-7 and A549 cells (marked with arrows). Briefly, cells were treated with Z-DAN-11 $(10 \mu \mathrm{M})$ for the indicated time points. After fixation, cells were stained with TUNEL and counterstained with DAPI for visualization of nuclei. Images were obtained in Leica confocal microscope (magnification: $\times 40$ ). $\mathbf{d}$ Microscopic images of JC1 staining in MCF-7 cells indicating Z-DAN-11-induced time-dependent and concentration-dependent increase in the mitochondrial permeability which is evident from the red to green shift of fluorescence. e Flow cytometric data showing time-dependent and concentrationdependent increase in intracellular ROS in MCF-7 cells in response to the treatment of Z-DAN-11. Post treatment, DCFDA (5 $\mu$ M final) in serum-free media was added and incubated for $30 \mathrm{~min}$; cells were scrapped out and washed in 1× PBS. Finally the fluorescent signals from the cells were acquired by FACS-Verse. $\mathbf{f}$ Microscopic images of MitoSOX ${ }^{\mathrm{TM}}$ Red staining in MCF-7 cells demonstrating Z-DAN-11-induced time-dependent and concentration-dependent increase in the mitochondrial ROS as evident from increase in red fluorescence. Briefly, cells grown on coverslips were fixed with $3.7 \%$ formaldehyde, were washed with $1 \times$ PBS and DAPI staining was done. Coverslips with stained cells were mounted on slides and observed in Leica confocal microscope 
staining also revealed profound DNA damage caused by Z-DAN-11 (Fig. S4c). Moreover, we investigated the effect of Z-DAN-11 on mitochondrial damage by JC-1 staining which showed a drastic alteration of the redox status of cellular mitochondria in response to Z-DAN-11 in a concentration-dependent and time-dependent manner both in MCF-7 and A549 cells (Fig. 4d and Fig. S5a).The shift of fluorescence from red to green or a decrease in the red/green ratio indicated the increase in the mitochondrial permeability in response to Z-DAN-11. In addition to that we also checked both cellular (Fig. 4e and Fig. S5b) and mitochondrial ROS (Fig. 4f and Fig. S5c) production in response to Z-DAN-11 which showed dosedependent and time-dependent increase in cellular as well as mitochondrial ROS. Our observation showed that pretreatment of $10 \mathrm{mM} \mathrm{N}$-Acetyl-Cysteine (NAC) was not only able to reduce Z-DAN-11-mediated mitochondrial ROS (Fig. 5a and Fig. S5d) but also decreased cancer cell apoptosis significantly (Fig. 5b and Fig. S5e), thereby confirming that Z-DAN-11-mediated cancer cell apoptosis is due to increased ROS production.

\section{Z-DAN-11 perturbs the balance in the pro-apoptotic/anti-} apoptotic signaling to induce apoptosis in cancer cells

A time-dependent proteome profile was performed with MCF-7 cells treated with Z-DAN-11 using the Proteome Profiler" Human Apoptosis Array Kit (R\&D Bio-system), as shown in Fig. 5c,d and Fig. S4d. Proteome profiler data revealed Z-DAN-11-mediated time-dependent increase in the expression of several pro-apoptotic proteins (Fig. $5 \mathrm{c}, \mathrm{d}$ ) like Bax, p21/cip, and cleaved caspase 3, and decrease in a number of anti-apoptotic (survival) proteins (Fig. 5c,d) namely, Survivin, Claspin, c-IAP, and Bcl-2. Although TNFR1 expression did increase significantly at $24 \mathrm{~h}$ (Fig. 5c,d), interestingly it decreased to almost normal levels by $72 \mathrm{~h}$. Figure $5 \mathrm{~d}$ represents mean pixel densities of each protein from two separate proteome profile experiments. A time-dependent induction in phosphorylation of p53 was observed at ser15, ser46, and ser392 (Fig. 5c,d) in Z-DAN-11 treated cells versus the control cells, indicating a possible p53 dependency in Z-DAN-11-mediated apoptosis. Thus, these results suggest induction of an apoptotic cascade involving an imbalance between proapoptotic and anti-apoptotic proteins, which may be p53 dependent.

\section{Z-DAN-11-mediated apoptosis of cancer cells involve both intrinsic and extrinsic pathway}

Since, mitochondrial damage (Fig. 4d and Fig. S5a) play a critical role in apoptosis signaling ${ }^{22}$, the effect of ZDAN-11 on the levels of key mediators regulating mitochondrial damage were assessed. Western blot data suggest increase in cytosolic AIF (apoptosis-inducing factor) expression with time in both MCF-7 as well as A549 cells time dependently in response to Z-DAN-11 (Fig. 6a), as well as over-expression of the pro-apoptotic proteins Bax, while Bcl-2 expression was significantly lowered (Fig. 6a). Z-DAN-11 also lowered the expression of anti-apoptotic proteins Survivin and Claspin (Fig. 6a). Since, Z-DAN-11induced DNA fragmentation (Fig. 4c and Fig. S4b-c) expression profile of critical proteins associated with maintenance of genomic integrity was studied in response to treatment with the compound. Z-DAN-11 treatment showed significant decrease in Chek1 expression time dependently (Fig. 6a). More importantly, while level of pchek1 (ser317) was elevated at early time points, significant decrease in p-chek1 was observed at later time points (Fig. 6a). Marked lowering in expression of Claspin, a DNA-binding protein critical for phosphorylation and activation of the Chek1 protein kinase by ATR in response to DNA damage ${ }^{23}$, was observed in Z-DAN-11-treated conditions versus control (Fig. 6a). These data were corroborated with an elevated expression of the DNA fragmentation marker $\gamma$-H2A.X in MCF-7 as well as A549 cells (Fig. 6a). A time-dependent induction in p53 as well as p-p53 ser15 was observed (Fig. 6a) which correlated to the proteome profiler data (Fig. 5c,d).The p21/cip expression increased time dependently while level of $\mathrm{p}$ p21 (Thr145) increased at early time points but significant decrease was observed at later time points. TNFR1 showed profound increase in expression in response to Z-DAN-11 in MCF-7 as well as A549 cells (Fig. 6b), which correlated with time-dependent increase in both FADD and TRADD expression, suggesting formation of the death-inducing signaling complex (DISC). Confirmation of recruitment of the DISC was obtained from Co-IP data (Fig. 6c), where TNFR1 immunoprecipitated with both TRADD as well as FADD in a timesensitive manner, following Z-DAN-11 treatment in MCF-7 cells.

\section{Induction of Z-DAN-11-mediated apoptosis involves activation of the caspase cascade leading to PARP1 cleavage}

The activation of caspase 3 was demonstrated by a timedependent increase in expression of corresponding cleaved caspase 3 accompanied with decrease in their proform both in MCF-7 and A549 cells (Fig. 6d) following treatment with Z-DAN-11(10 $\mu \mathrm{M})$ at several time points (6-72 h). However, in both cells the activation of caspase 7 and caspase 8 were evident from decreased expression of their pro-form after $36 \mathrm{~h}$ of treatment (Fig. 6d). Further, Z-DAN-11 was found to downregulate pro-caspase 9 levels time dependently, indicating activation of caspase 9 and thereby suggesting mitochondrial involvement in ZDAN-11-mediated apoptosis. The activity assay also confirmed activation of caspase 3/7 in MCF-7 and A549 cells at later time points $(36,48$, and $72 \mathrm{~h})$ as shown in 


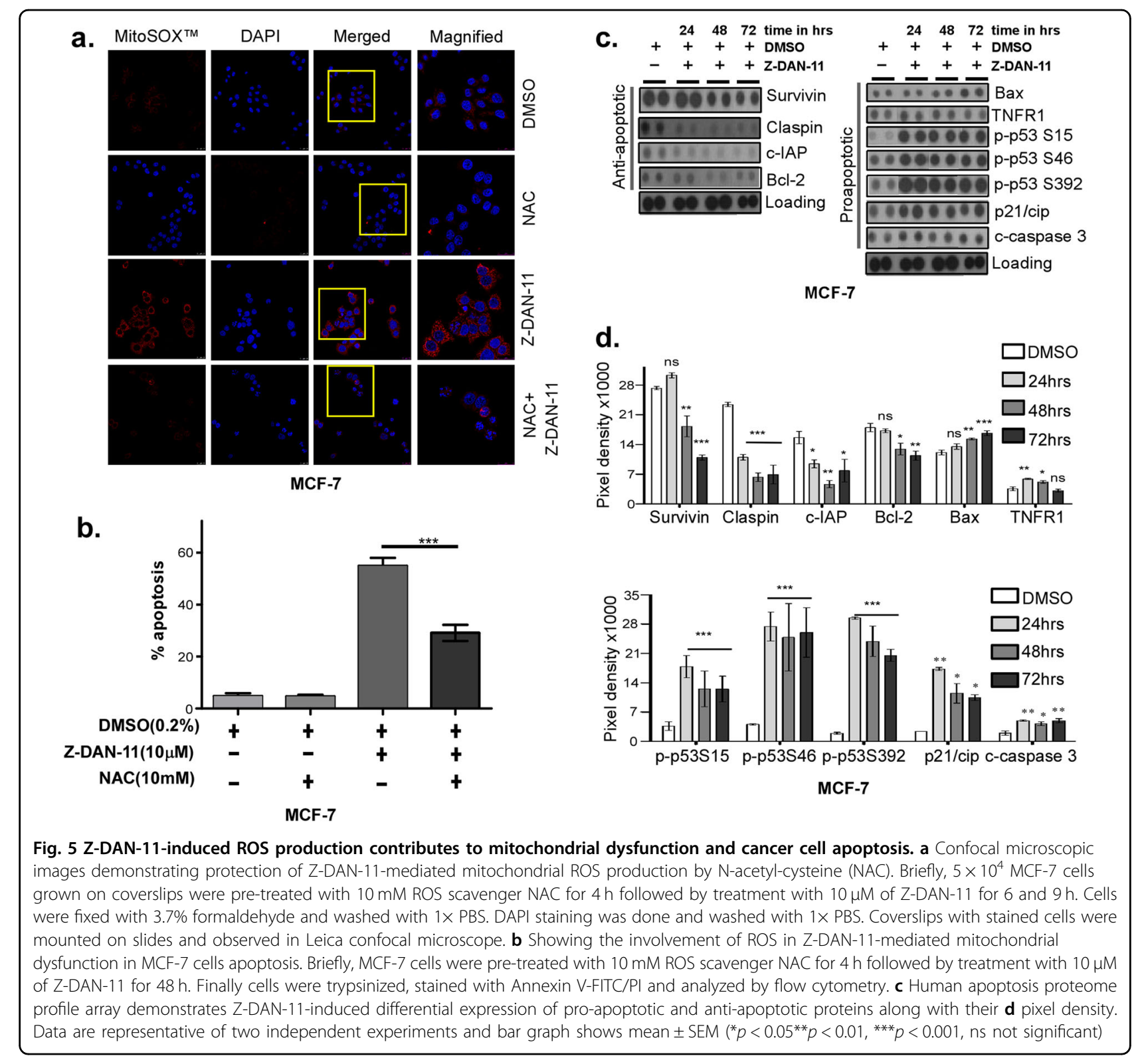

Fig. 6e. Additionally, cleavage mediated deactivation of PARP1 was observed in both MCF-7 as well as A549 cells (Fig. 6d). Importantly, MCF-7 and A549 pretreated with $20 \mu \mathrm{M}$ each of the corresponding inhibitors for caspase 3 (Z-DEVD-FMK), caspase 8 (Z-IETDFMK), and PAN-caspase (Z-VAD-FMK) conferred significant protection to the cells from Z-DAN-11mediated apoptosis as evidenced from Fig. 6f, confirming that Z-DAN-11-mediated tumor cell apoptosis was caspase dependent. Collectively these results suggest that Z-DAN-11 involves both the extrinsic and intrinsic pathway causing mitochondrial damage, activation of caspases leading to PARP1 cleavage, DNA damage, and eventually tumor cell apoptosis.

\section{Z-DAN-11-mediated apoptosis of tumor cells is p53 dependent}

Since, proteome profiler followed by western blot analysis indicated time-dependent phosphorylation of p53 (Fig. 5c,d and Fig. 6a), we wanted to confirm the role of p53 in Z-DAN-11-mediated apoptosis of tumor cells. While in $\mathrm{p} 53^{\mathrm{wt}}$ HCT116 cells, Z-DAN-11 caused a significant induction of apoptosis $(>40 \%$ Annexin $\mathrm{V}+\mathrm{ve}$ cells shown in Fig. $7 \mathrm{a}, \mathrm{b})$, in the p53 $3^{-1-}$ HCT116 cells it is significantly lower (around 27\% Annexin V+ve cells), thereby confirming that p53 plays a definitive role in ZDAN-11-mediated death of tumor cells. This was further confirmed by silencing p53 levels in both A549 and MCF-7 cell line using specific siRNAs targeted against 


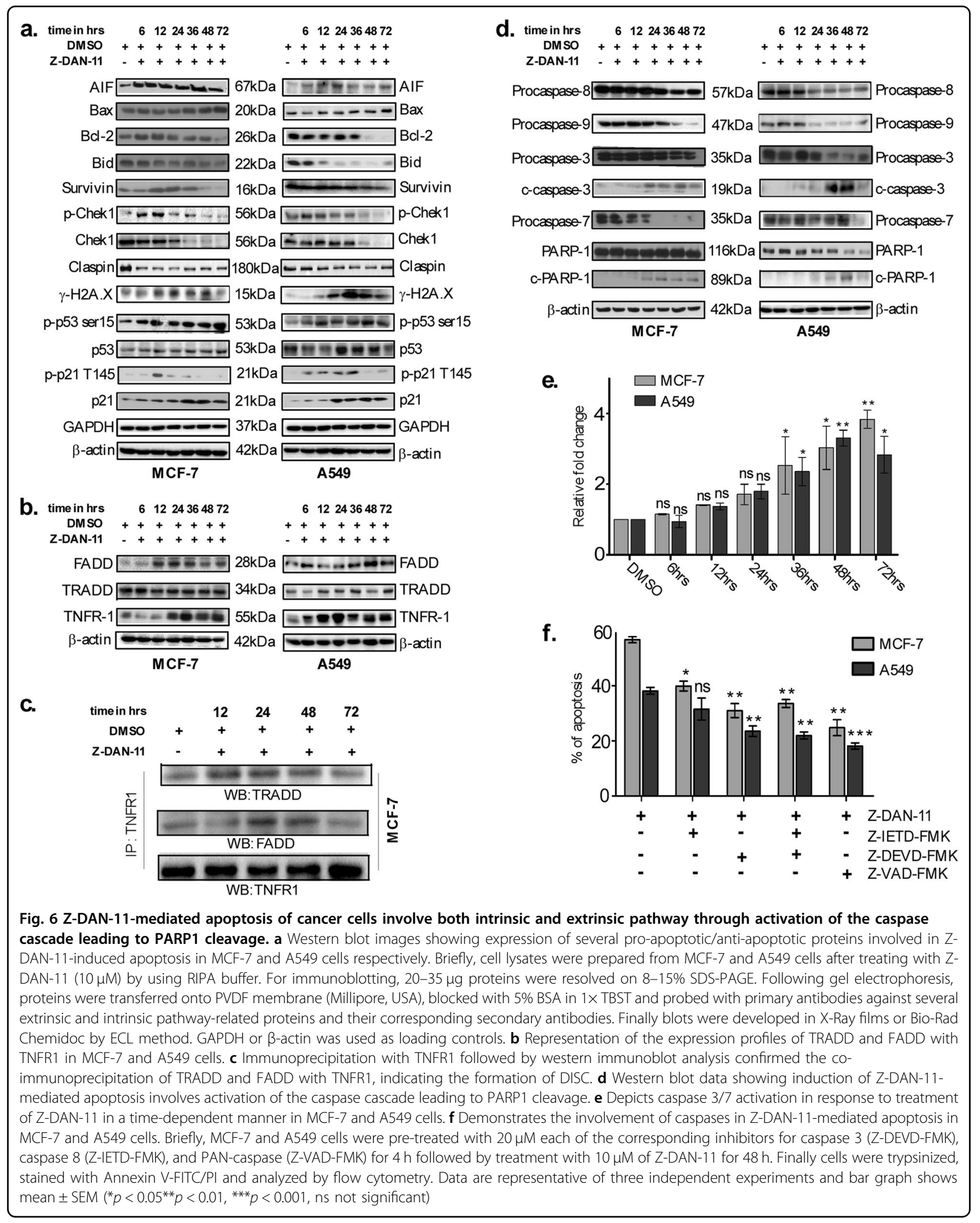


a.

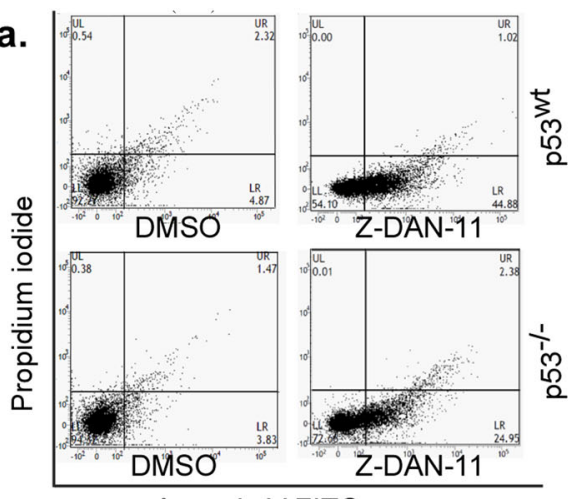

Annexin V-FITC

b.

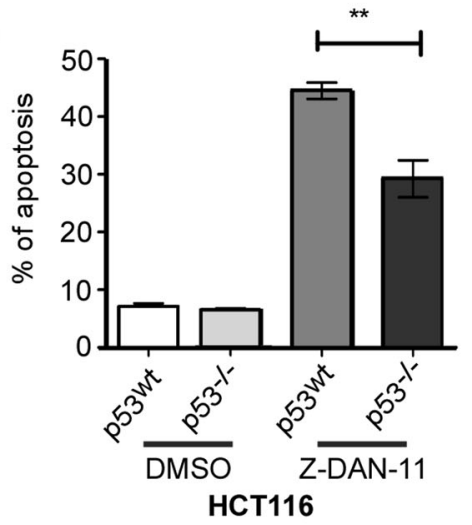

c.

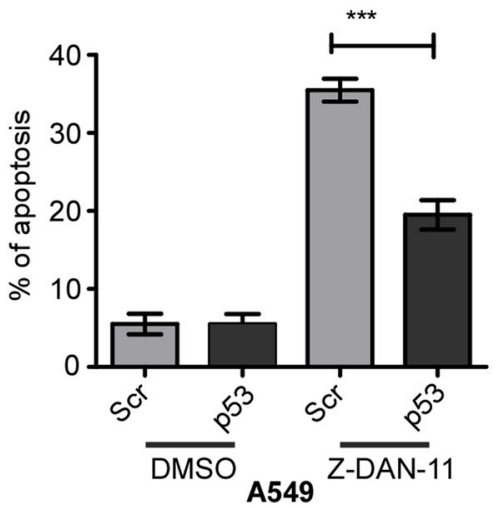

d.

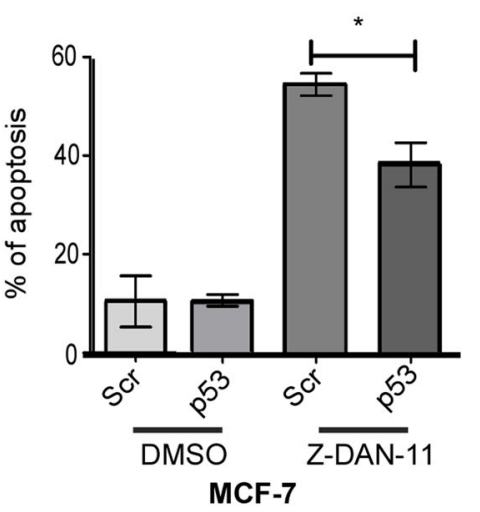

e.

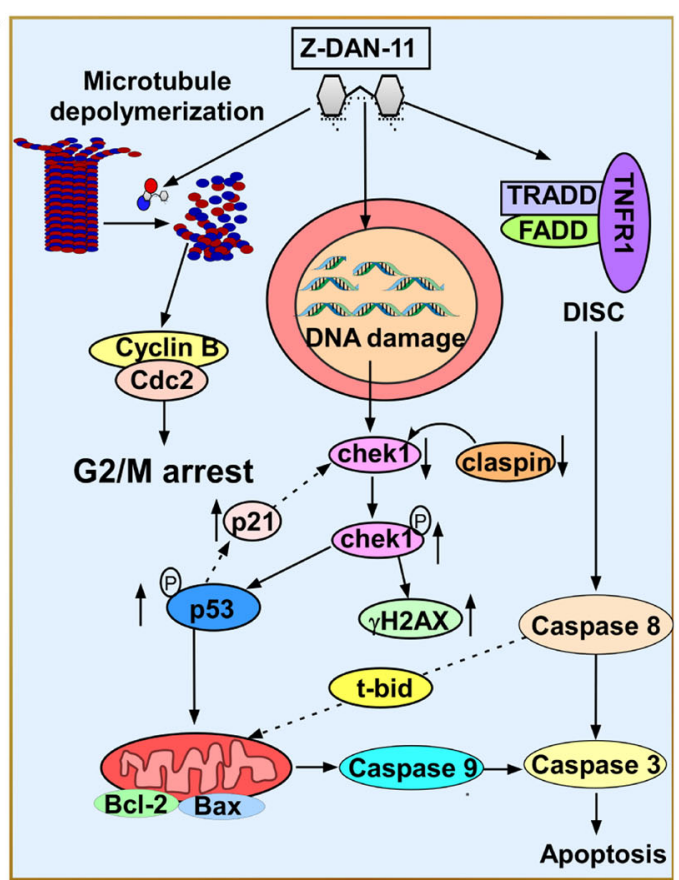

Fig. 7 Z-DAN-11-mediated apoptosis of tumor cells is p53-dependent. a Depicts a representative density plot showing that Z-DAN-11-mediated apoptosis is significantly reduced in HCT116 $\mathrm{p} 53^{-/-}$cells compared to HCT116 $\mathrm{p} 53^{\text {wt }}$ cells along with $\mathbf{b}$ bar graph representing mean \pm SEM $\left({ }^{*} p>\right.$ $0.05,{ }^{* *} p<0.01,{ }^{* *} p<0.001$, ns not significant) of at least three independent experiments. Bar diagram showing that Z-DAN-11-mediated apoptosis is blocked in p53 siRNA transfected $\mathbf{c}$ A549 and $\mathbf{d}$ MCF-7 cells compared to the scrambled. Data are represented as mean \pm SEM ${ }^{*} p>0.05,{ }^{* *} p<0.01$, ${ }^{* * *} p<0.001$, ns not significant). e A schematic signaling model proposing how Z-DAN-11-mediated proliferation inhibition is associated with G2/M arrest and apoptosis. Z-DAN-11 binds to tubulin and induces microtubule depolymerization which leads to G2/M arrest. On the other hand Z-DAN11-induced DNA damage contribute to apoptosis through intrinsic and extrinsic pathways involving chek1, p53, TNFR1, TRADD, FADD etc. and downstream activation of caspase 8, caspase 9, and caspase 3 leading to apoptosis

p53, which conferred significant protection from ZDAN-11-mediated apoptosis, in A549 (nearly 50\% lower than the scrambled, Fig. 7c) and MCF-7 (nearly 35\% lower, Fig. 7d) p53-siRNA-transfected cells. Together, these experiments confirmed that Z-DAN-11-mediated tumor cell apoptosis is at least partly but significantly p53-dependent. Taken together, these results suggest ZDAN-11 depolymerizes microtubules leading to G2/M arrest, and at the same time induce DNA damage, leading to p53-dependent induction of the apoptotic 


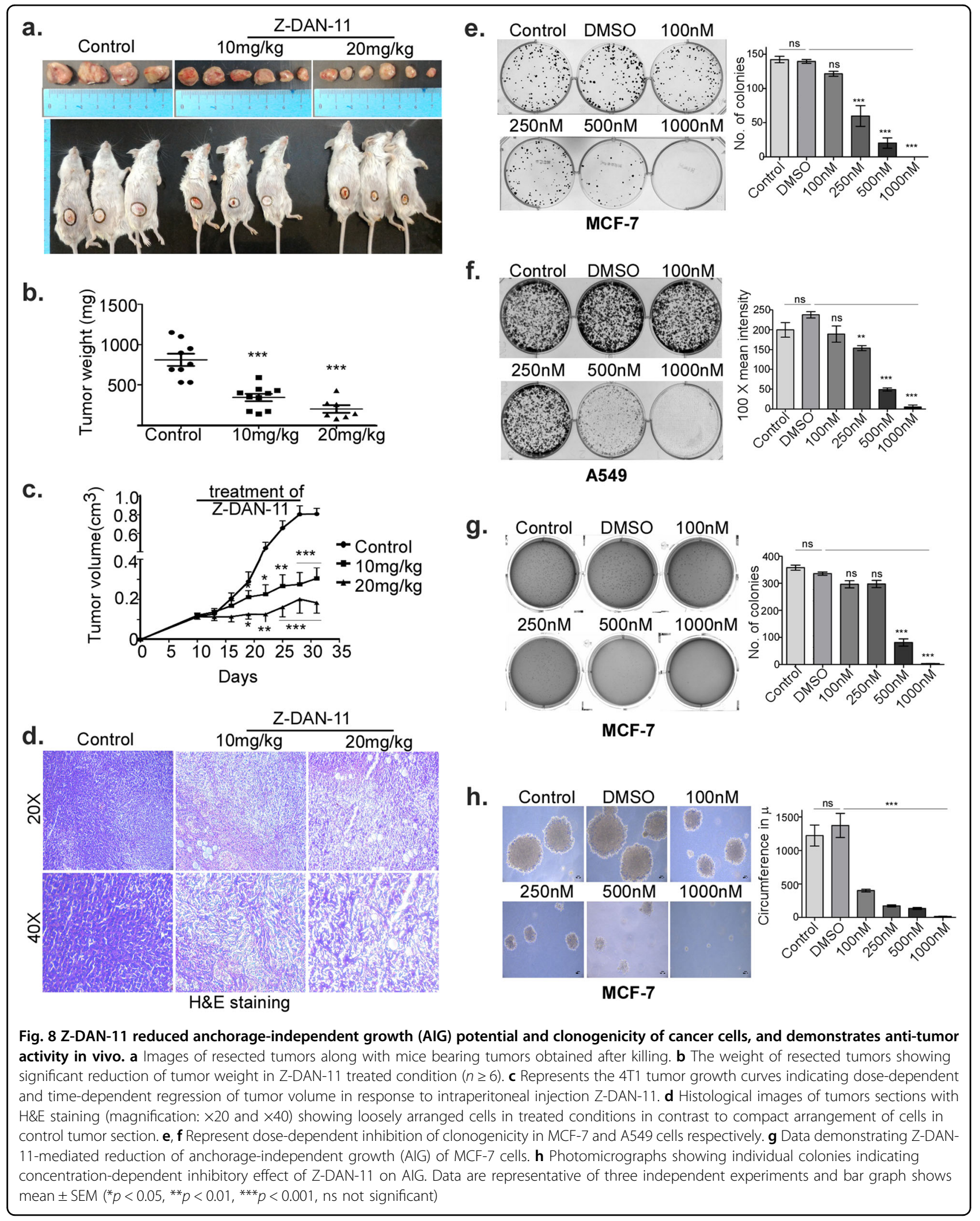


cascade that involves both the intrinsic as well as the extrinsic pathway (Fig. 7e).

\section{Z-DAN-11 caused significant reduction in tumor growth and progression in immuno-competent mice}

In vivo data shows a significant dose-dependent inhibition of tumor growth as evidenced from the reduction in tumor volume as shown in Fig. 8a, demonstrating that mice treated with either $10 \mathrm{mg} / \mathrm{kg}$ or $20 \mathrm{mg} / \mathrm{kg}$ b.w. of Z-DAN-11 have significantly smaller tumor size than the non-treated mice. This is also reflected in the weight of resected tumors from mice treated with Z-DAN-11, which shows dose-dependent decrease in the tumor weight compared to the nontreated mice (Fig. 8b). Z-DAN-11 also caused a dosedependent decrease in tumor progression with time, as shown in Fig. 8c. Microscopic analysis of tumor section with $\mathrm{H}$ and $\mathrm{E}$ staining showed compact arrangement of cells in control tumor section in contrast to loosely arranged cells in treated conditions. Additionally, more eosin-stained cells were observed in treated condition as compared to control tumor (Fig. 8d). However, there seems to be no significant change in total body weight of mice or the serum levels of alanine transaminase (ALT), aspartate transaminase (AST), creatinine, urea and alkaline phosphatase (ALP), either treated or non-treated, as shown in Fig. S6a. The pharmacokinetics of ZDAN-11 showed $11.23 \pm 0.68 \%$ of absolute bioavailability (Fig. S6b).

\section{Z-DAN-11 reduced anchorage-independent growth (AIG) potential and clonogenicity of cancer cells}

Z-DAN-11 significantly inhibits colony forming ability of the tumor cells at concentrations as low as $250 \mathrm{nM}$ in case of MCF-7 (Fig. 8e) and $500 \mathrm{nM}$ in case of A549 cells (Fig. 8f), with a complete abrogation of colony forming ability of both cells at $1 \mu \mathrm{M}$ dose of Z-DAN-11 (Fig. 8e,f). Moreover, Z-DAN-11 exhibited inhibition of anchorageindependent growth (AIG) of tumor cells at $500 \mathrm{nM}$ and above (Fig. 8g); indicating Z-DAN-11 treatment results in a loss of ability of the tumor cells to grow anchorage independently. A dose-dependent reduction in the size of individual colonies was evident from the photomicrographs shown in Fig. 8h.

\section{Discussion}

One of the major obstacles of cancer chemo-prevention is undesirable toxicity to the normal cells, thereby resulting in adverse side-effects. This study was aimed in identification of a possible candidate with potent chemotherapeutic potential and minimal toxicity. Here, we synthesized a series of trans-stilbene derivatives and identified at least one derivative, named Z-DAN-11 which blocked cellular proliferation selectively in a series of different cancer cell lines in vitro, concentration dependently (Fig.1a-e and Table S1).

Functionally, Z-DAN-11-arrested tumor cells in the G2/ M-phase both time and dose dependently (Fig. 2a-d and Fig. S2a-b). Z-DAN-11 caused a time-dependent decrease in cdc2, cdk2 and their phosphorylation, which are classical molecular signatures (Fig. 3g) leading to progression through the G2/M-phase, thereby confirming that ZDAN-11 induces G2/M-phase arrest. Again as microtubule dynamics is essential for cell cycle regulation, perturbation of which triggers cell cycle arrest and apoptosis $^{24-27}$. Mechanistically, Z-DAN-11 caused a significant downregulation of $\beta$-tubulin (Fig. 3e and Fig. S2e) similar to nocodazole. These results indicate that Z-DAN11 drives G2/M arrest through microtubule depolymerization which may provide a possible strategy to reverse cell cycle-mediated drug resistance through synchronization of cells ${ }^{28}$.

Moreover, induction of cell cycle arrest was accompanied by a parallel induction of apoptosis, as evidenced from a dose-dependent increase in the number of annexin V/PI and TUNEL positive cells (Fig. 4a-c and Fig. S4a-b). Our experimental evidences (Fig. 4d-f and Fig. S5a-c) confirmed role of Z-DAN-11-mediated ROS generation in dramatic alteration of the mitochondrial redox status that critically contribute to apoptosis, as NAC was able to reduce Z-DAN-11-mediated apoptosis significantly (Fig. 5a,b and Fig. S5d-e). These data clearly suggests that Z-DAN-11-induced ROS production contributes to mitochondrial dysfunction which leads to the cancer cell apoptosis through involvement of both, intrinsic as well as extrinsic pathways. This was confirmed from increase in expression of mediators (Fig. 5c,d and Fig. 6a-d) that leads to mitochondrial damage (Fig. $4 \mathrm{~d}$ and Fig. S5a), activation of caspases (Fig. 6d,e) and PARP1 cleavage.

Our findings (Fig. 6a) showed time-dependent decrease in expression of claspin along with a significant decrease in the expression of total chek1 and p-chek1 (ser317) in response to Z-DAN-11 treatment. This was associated with an elevated expression of $\gamma$-H2A.X (Fig. 6a), which may provide a possible link between the observed apoptosis and G2/M-phase arrest mediated by Z-DAN-11 treatment. Further, since inhibition of chek1 was known to cause G2 abrogation thereby selectively promoting apoptosis in cancer cells but not in normal cells ${ }^{29}$, ZDAN-11-mediated chek1 inhibition may also explain the selective cytotoxicity of the compound observed earlier. Thus, chek1 plays a critical role in the observed G2/M arrest, DNA fragmentation and subsequent Z-DAN-11induced apoptosis. As p53 phosphorylation at ser15 (DNA damage response) ${ }^{30,31}$, ser46 (induction of apoptosis) (2,33 $^{32}$ and ser392 (growth suppression) ${ }^{34}$ play important role in cell proliferation. Interestingly, from proteome profiler and western immunoblot data, we found increased levels 
of total p53 along with p-p53 ser15, ser46, ser392 as shown in Fig. 5c,d and Fig. 6a, suggesting a critical role of p53 in Z-DAN-11-mediated apoptosis. Significant reduction of Z-DAN-11-mediated apoptosis both in p53 ${ }^{-1-}$ cells (Fig. 7a,b) as well as siRNA-mediated p53-silenced A549 and MCF-7 cells (Fig. 7c,d), confirmed the involvement of p53 in Z-DAN-11-mediated apoptosis. Finally, to establish Z-DAN-11 as an effective anti-cancer lead, we investigated its therapeutic efficacy in a syngeneic mouse tumor model, using 4T1 cells on a Balb/c background. Z-DAN-11-regressed tumor volume as well as tumor weight (Fig. 8a-C) without significant adverse effect on animals (Fig. S6a). Thus, we have identified a novel synthetic trans-stilbene resveratrol derivative with potent anti-tumor activity, the mechanism behind which is its ability to selectively block tumor cell proliferation and induce tumor cell apoptosis, but not normal cells. Hence, Z-DAN-11 may be a promising candidate for targeted and selective therapeutic strategy against cancer.

\section{Materials and methods Chemicals and reagents}

Chemicals and reagents were obtained from SigmaAldrich (USA), Merck (India), Invitrogen (India), Himedia (India), and SRL (India). Primers and DCFDA (\#D6883) were purchased from Sigma (India). p53 si-RNA (\#sc29435) and purified porcine tubulin (\#T240) was bought from Santa Cruz Biotechnologies (USA) and Cytoskeleton (USA), respectively. MitoSOX ${ }^{\mathrm{mw}}$ (\#M36008) was procured from Thermo Fisher scientific (USA). Various primary antibodies $\alpha$-tubulin (\#2125), $\beta$-tubulin (2146), Cdc2 (\#9116), phospho-Cdc2 (\#9111), Cdk2 (\#2546), cyclin B1 (\#4138), p-H3 ser10 (\#9706), AIF (\#5318), TRADD (\#3994), FADD (\#2782), TNFRI (\#3736), Bax (\#3994), survivin (\#2808), $\gamma-H 2 A . X(\# 80312), \quad$ p53 (\#2524), p-p53 (\#9286), p21 (\#2947), cleaved caspase 3 (\#9664), caspase 7 (\#9494), caspase 8 (\#9746), caspase 9 (\#9508), Bid (\#2002), and PARP1 (\#9532) were obtained from Cell Signaling Technologies, USA. Chek1 (\#AF1630), p-chek1 (\#AF2054), claspin (\#MAB3310) antibodies, and human apoptosis proteome profiler kit (\#ARY009) were purchased from R \& D Bio-systems. Cyclin A1 (\#sc56301), phospho-p21 (\#sc-377569) and Bcl-2(\#sc7382) were brought from Santa Cruz Biotechnologies (USA). Loading controls GAPDH and $\beta$ actin were procured from Imgenex (India). Cdk2 (\#ab6433), phospho-Cdk2 (\#ab76146), phospho-Cyclin B1 (\#ab133439), caspase 3 colorimetric assay kit (\#ab39401) was obtained from Abcam (USA). Inhibitors to caspase 3 (Z-DEVD-FMK \#sc3075), caspase 8 (Z-IETD-FMK \#sc3084), and Pan-caspase (Z-VAD-FMK \#sc3067) were ordered from Santa Cruz Biotechnologies (USA). Fetal bovine serum (\#16000044) was bought from Gibco, USA and L-glutamine, Gentamicin, MEM sodium pyruvate; MEM non-essential amino acids were procured from $\mathrm{Hi}-$ Media, India.

\section{Cell culture and maintenance}

MCF-7, MDA-MB-231, MDA-MB-468, T47D, HBL100 (human breast cancer cells), HeLa (human cervical cancer cells), WI-38 (human lung fibroblast cells), A549 (human lung adenocarcinoma cells), HCT116 p53 ${ }^{\mathrm{wt}}$, HCT116 p53 $3^{-1-}$ (human colon carcinoma cells), PC3 (prostate cancer) and 4T1 (murine mammary carcinoma) cell lines were procured from the central cell repository of National Center for Cell Science (NCCS), Pune, India and cultured as suggested by the supplier. Human renal cell carcinoma (RCC) cell lines SK-RC-45 and NKE cell were obtained from Dr. Gerd Ritter (Ludwig Institute of Cancer Research, USA) and Dr. James H. Finke (Cleveland Clinic Foundation, USA) respectively. All the above cell lines were cultured either in RPMI 1640 or DMEM, containing 10\% FBS, $1 \mathrm{mM}$ sodium pyruvate, $2 \mathrm{mM}$ L-glutamine, non-essential amino acids, 100 units/L penicillin, $100 \mathrm{mg} / \mathrm{L}$ streptomycin, and $50 \mathrm{mg} / \mathrm{L}$ gentamycin sulfate at $37{ }^{\circ} \mathrm{C}$ with $5 \%$ $\mathrm{CO}_{2}$.

\section{Synthesis of trans-stilbene compounds}

Briefly, to an ice-cold solution of aryl acetonitriles (1-4) $(1 \mathrm{mmol})$ and aldehydes $(5-19)(1.1 \mathrm{mmol})$ in $\mathrm{EtOH}(10$ $\mathrm{mL})$ was added $5 \%$ aq. $\mathrm{NaOH}(0.2 \mathrm{~mL})$ and the reaction mixture was briskly stirred at room temperature for 30 min. Acidification of the reaction mixture using $1 \mathrm{~N} \mathrm{HCl}$ led to the formation of products as solids. Filtration of the solid products and re-crystallization from $\mathrm{EtOH}$ furnished pure products Z-DAN-1-Z-DAN-22.

\section{MTT cell proliferation assay}

In order to determine the effect of the synthesized compounds on cell proliferation, MTT assay was performed $^{35,36}$. Briefly, cells were grown in 96 well plate in presence of the synthesized (Z) -2, 3-diarylacrylonitrile (trans-stilbene) derivatives $(0-60 \mu \mathrm{M})$ for 48 h. 5\% FBScontaining phenol red-free DMEM and MTT $(200 \mu \mathrm{L} ; 0.5$ $\mathrm{mg} / \mathrm{mL}$ ) were added to each well and incubated at $37^{\circ} \mathrm{C}$ for $4 \mathrm{~h}$ in a humidified incubator containing $5 \% \mathrm{CO}_{2}$. The purple-colored formazan crystals formed in the wells were dissolved in DMSO and absorbance was measured at 570 $\mathrm{nm}$ with a microplate reader.

\section{Trypan blue exclusion method}

Trypan blue exclusion is technique which classifies viable and nonviable cells based on membrane integrity. A viable cell with intact membrane will not take trypan blue whereas a nonviable cell will have trypan blue positive cytoplasm $^{37}$. Post treatment, $1 \times$ PBS resuspended cells 
were mixed with $0.4 \%$ trypan blue solution in 1:1 dilution for $4 \mathrm{~min}$ and counted with hemocytometer.

\section{Cell cycle profiling assay by propidium iodide staining}

For this experiment, double thymidine blocked ${ }^{38}$ synchronized human cancer cells including MCF-7, MDAMB-231, A549, and HeLa were treated with increasing concentrations $(0.5 \mu \mathrm{M}, 1 \mu \mathrm{M}, 2.5 \mu \mathrm{M}, 5 \mu \mathrm{M}$, and $10 \mu \mathrm{M})$ of Z-DAN-11 for $24 \mathrm{~h}$. Nocodazole was used as a reference control for this experiment ${ }^{39,40}$. Post treatment, cells were harvested into single cell suspension and fixed by incubating the cells overnight at $-20^{\circ} \mathrm{C}$ with $75 \%$ ethanol. Cells were centrifuged and resuspended in $1 \times$ PBS for $2 \mathrm{~h}$ followed by RNaseA $(20 \mu \mathrm{m})$ treatment for $2 \mathrm{~h}$ at $37^{\circ} \mathrm{C}$. Finally, propidium iodide was added and incubated for 20 min at room temperature. Flow cytometric analysis was immediately performed using a FACS-Verse instrument (BD).

\section{Microarray}

Affymetrix PrimeView ${ }^{\mathrm{Tm}}$ Human Gene Expression Array platform was used to check the differential expression of gene sets in response to Z-DAN-11. Microarray data sets were analyzed using TM4:Microarray Software suite ${ }^{41}$. Gene-level signal estimates were derived from the raw data files. The 'affy' package in $\mathrm{R}$ were used to quantile normalize and background adjust the raw CEL files by implementing the Robust Multichip Averaging algorithm. SAM analysis was performed to determine the statistically significant differentially expressed genes between the test and the control groups, using default statistical parameters. Genes with FDR-adjusted $p$ values $\leq 0.05$ were further screened to get the final set of DRGs based on fold change $\geq 2$ between test and the control groups. Hierarchical clustering was performed by complete linkage and Pearson's correlation using Cluster $3.0^{42}$; results were visualized using Java TreeView (http://jtreeview. sourceforge.net/).

\section{RNA isolation and real-time PCR}

Total RNA was extracted using Trizol reagent (Invitrogen). cDNA was prepared from $1 \mu$ g of RNA extracted from MCF-7 cells treated with $10 \mu \mathrm{M}$ dose of Z-DAN-11 for 6,12 , and $24 \mathrm{~h}$ along with DMSO-treated control using Verso cDNA synthesis kit (Thermo Scientific). RTPCR was performed using SYBR green PCR system on 7500 fast (Applied Biosystem). All mRNA quantification data were normalized to $\beta$-actin. Real-time primers were listed in Figure S3c.

\section{Immunocytochemistry}

Immunocytochemistry was performed as described previously $^{43}$. Briefly, $5 \times 10^{3}$ cells grown on coverslips were fixed with $3.7 \%$ paraformaldehyde, washed with $1 \times$
PBS and stained with primary antibody (1:100) overnight at $4{ }^{\circ} \mathrm{C}$. Cells were washed with $1 \times \mathrm{PBS}$, counterstained with Alexaflour-488/594 secondary antibody (1:500) for 1 $\mathrm{h}$ at room temperature. Finally, DAPI staining was done and washed with $1 \times$ PBS. Coverslips with stained cells were mounted on slides and observed in Leica confocal microscope.

\section{In vitro microtubule polymerization assay}

Purified porcine tubulin $(15 \mu \mathrm{M})$ was incubated with or without the compounds in tubulin polymerization buffer PEM (80 mM PIPES, $0.5 \mathrm{mM} \mathrm{MgCl} 2,1 \mathrm{mM}$ EGTA, pH 6.8) with $10 \%$ DMSO in ice for $10 \mathrm{~min}$. Subsequently, 1 $\mathrm{mM}$ (GTP) was added and kinetic loop study was done using Thermo scientific Multiscan Go Multi Plate reader set at $37^{\circ} \mathrm{C}$ temperature. The polymerization was monitored over $60 \mathrm{~min}$ by measuring the absorbance at 340 nm.

\section{Annexin V-FITC/PI staining}

Induction of apoptosis was measured by flow cytomety after annexinV-FITC/PI staining ${ }^{44}$ using BD Bioscience kit. Briefly, post treatment $0.5 \times 10^{6}$ cells were washed in ice-cold $1 \times$ PBS and resuspended in $100 \mu \mathrm{L}$ of binding buffer and incubated with $5 \mu \mathrm{L}$ of annexin V-FITC and 5 $\mu \mathrm{L}$ of PI for $15 \mathrm{~min}$ at room temperature in a dark place as per manufacturer's guidelines. Flow cytometric analysis was immediately performed using a FACS-Verse instrument (BD).

\section{JC1 staining}

Assessment of mitochondrial permeability was measured by JC1 staining as described earlier ${ }^{45}$. MCF-7 cells were treated with test compounds $(0,2.5,5$, and $10 \mu \mathrm{M})$ for 6 and $9 \mathrm{~h}$. Cells were washed with $1 \times$ PBS buffer and incubated with the JC- 1 dye $(3 \mu \mathrm{M}$ final concentration in DMEM media) at $37^{\circ} \mathrm{C}$ for $30 \mathrm{~min}$ in the dark. Cells were again washed twice with $1 \times$ PBS buffer and kept back in $1 \times$ PBS buffer. Finally images were captured with Leica fluorescent microscope.

\section{Measurement of mitochondrial ROS by using MitoSOX ${ }^{\mathrm{mm}}$}

MitoSOX ${ }^{\mathrm{m}}$ Red mitochondrial superoxide indicator is a novel fluorogenic dye for highly selective detection of superoxide in the mitochondria of live cells ${ }^{46}$. For this experiment briefly, $5 \times 10^{4}$ cells grown on coverslips were fixed with $3.7 \%$ formaldehyde, washed with $1 \times$ PBS and DAPI staining was done. Coverslips with stained cells were mounted on slides and observed in Leica fluorescence microscope.

\section{Measurement of cellular ROS using DCFDA \\ Intracellular ROS was measured using DCFDA method $^{47}$. MCF-7 and A549 cells were treated with test}


compounds $(0,2.5,5$, and $10 \mu \mathrm{M})$ for 6 and $9 \mathrm{~h}$. After treatment, the media was discarded and serum-free media was added. Then DCFDA ( $5 \mu \mathrm{M}$ final) was added and incubated for $30 \mathrm{~min}$. Post incubation the media was discarded and adherent cells were scrapped out and washed in $1 \times$ PBS. Finally, the fluorescent signals from the cells were acquired by FACS-Verse.

\section{Human apoptosis proteome profiler array}

Expression pattern of several pro-apoptotic and antiapoptotic proteins were examined in Z-DAN-11 $(10 \mu \mathrm{M})$ treated and DMSO-treated MCF-7 cells for 24, 48, and 72 h by using Human apoptosis array kit (R\&D Biosystem). An aliquot of $300 \mu \mathrm{g}$ of protein was used for each condition and experiment was as performed as described in our earlier report ${ }^{48}$. Thereafter, cell lysates were subjected to analysis using the Proteome Profiler ${ }^{\mathrm{TM}}$ human apoptosis antibody array according to the manufacturer's instructions. Arrays were developed with streptavidinHRP for $30 \mathrm{~min}$ on a rocking platform shaker. Developed signals were densitized using ImageJ software, pixel densities were normalized to untreated sample and expressed as mean pixel density.

\section{TUNEL assay}

Visual confirmation of apoptosis was achieved by using Terminal deoxynucleotidyl TUNEL assay ${ }^{45}$. For this experiment, $4 \times 10^{4}$ cells were grown to confluence with or without Z-DAN-11 $(10 \mu \mathrm{M})$ on coverslips, following which cells were washed with $1 \times$ PBS and fixed with prewarmed $3.7 \%$ formaldehyde. Cells were then permeabilized with $0.1 \%$ triton-X at $2-8{ }^{\circ} \mathrm{C}$ for 5 min. TUNEL reaction mixture was added to the cells and incubated for $1 \mathrm{~h}$ in the dark in humidified chamber. DAPI was used as counter stain. Microscopic analysis was done using a confocal microscope.

\section{Western immunoblotting}

Briefly, cell lysates were prepared from MCF-7 and A549 cells post treatment with Z-DAN-11 $(10 \mu \mathrm{M})$ with RIPA buffer method. For immunoblotting, 20-35 $\mu \mathrm{g}$ proteins were resolved on 8-15\% SDS-PAGE, transferred onto PVDF membrane (Millipore, USA), blocked with $5 \%$ BSA in $1 \times$ TBST, and probed with respective primary antibodies followed by corresponding secondary antibodies. Finally blots were developed into X-Ray films by ECL method or by using Chemidoc MP system Bio-Rad.

\section{Caspase 3/7 activation assay}

For this experiment cell lysates were prepared from MCF-7 cells after treating with Z-DAN-11 $(10 \mu \mathrm{M})$ with RIPA buffer method. An aliquot of $150 \mu \mathrm{g}$ of protein was used for each condition. DTT and DEVD-p-NA substrate were added according to manufactures protocol. Samples were mixed well and incubated at $37^{\circ} \mathrm{C}$ for $90 \mathrm{~min}$ and finally OD was measured at $405 \mathrm{~nm}$ in Thermo Multiskan $\mathrm{GO}$ microplate reader.

\section{Co-immunoprecipitation}

Co-immunoprecipitation was performed as described previously $^{49}$. Cells were lyzed in IP lysis buffer $(25 \mathrm{mM}$ Tris- $\mathrm{HCl} \mathrm{pH}$ 7.4, $150 \mathrm{mM} \mathrm{NaCl}, 1 \mathrm{mM}$ EDTA, 1\% NP-40, and $5 \%$ glycerol). A total of $400 \mu \mathrm{g}$ of protein lysates were incubated with rabbit monoclonal anti-TNFRI antibody ( $3 \mu \mathrm{g} /$ condition) overnight with continuous rotation. Next day, Protein A beads were added and incubated for another $4 \mathrm{~h}$. Then, beads were washed three times using lysis buffer. Finally, beads were resuspended in $40 \mu \mathrm{L}$ of $2 \times$ laemmli buffer, centrifuged at $13,000 \mathrm{rpm}$. Supernanants were collected and resolved on 12\% SDS-PAGE. Finally, western immunoblot was done with FADD, TRADD, and TNFRI antibodies.

\section{si-RNA transfection}

MCF-7 cells $\left(1.5 \times 10^{5}\right)$ were grown in 6 well plates in antibiotic-free media for $24 \mathrm{~h}$. Post incubation, p53 siRNA and scrambled were transfected with RNAi Max (Invitrogen) as per manufacturer's instructions. Cells were grown in opti-MEM for $6 \mathrm{~h}$ followed by incubation with complete DMEM for $24 \mathrm{~h}$.

\section{Soft agar colony formation assay and clonogenicity}

Clonogenic assay and Soft agar colony formation assay was performed as described earlier ${ }^{50}$. For soft agar assay, $2 \times 10^{4}$ cells were resuspended in $1 \mathrm{~mL} 2 \times$ complete DMEM and mixed with $1 \mathrm{~mL}$ warmed $0.7 \%$ agarose and plated over a solidified $0.75 \%$ agarose in $1 \times$ DMEM. Following solidification of the top layer, 2 mLof DMEM was added, incubated at $37^{\circ} \mathrm{C}$ for 30 days with continuous media change (with or without Z-DAN-11) in every 3rd day. Colonies were fixed, stained with $0.05 \%$ crystal violet and imaged using Gel Doc XR+ (Bio-Rad). For clonogenicity assay, cells were plated at very low density ( 200 cells/well in 6 well plate), grown for either 8/10 days, fixed with $3.7 \%$ formaldehyde, stained with $0.05 \%$ crystal violet, and image was captured using Gel Doc XR+ (Bio-Rad).

\section{T1 breast tumor model}

BALB/c mice 6-8-week-old were obtained from Center for Translational Animal Research (CTAR), Bose Institute, Kolkata, India and were maintained as per the guidelines of the animal ethical committee in accordance with CPCSEA guidelines (IAEC Approval No. IAEC/BI/ $32 / 2015$ Dt. 26/05/2015). For in vivo tumorigenic assay, $4 \mathrm{~T} 1$ cells $\left(1.5 \times 10^{6}\right.$ cells/animal $)$ were subcutaneously injected into the mammary fat pad of Balb/c mice to 
develop solid tumor. Animals with solid tumor were randomly distributed into three groups each containing six animals. One group was treated with vehicle control (10\% DMSO in normal saline) whereas; other two groups were given intraperitoneal injection of Z-DAN-11 $(10 \mathrm{mg} /$ $\mathrm{kg}$ and $20 \mathrm{mg} / \mathrm{kg}$ ) starting after 10 days of tumor development and continued until 31 days (seven doses, $72 \mathrm{~h}$ interval). Tumor progression was monitored by measuring the volume of the tumor with vernier calipers on every third day. The tumor volume was calculated by using the formula $V=0.5 \times a \times b^{2}$, where "a" and "b" indicate major and minor diameter, respectively ${ }^{51}$. Histopathological examination was performed by haematoxylin and eosin staining as described previously ${ }^{52}$.

\section{Hepatotoxicity and pharmacokinetics studies}

Following seven doses Z-DAN-11 $(10 \mathrm{mg} / \mathrm{kg}$ and $20 \mathrm{mg} /$ $\mathrm{kg}$ ) each with 3 days interval $100 \mu \mathrm{L}$ blood sample were taken manually into heparinized capillary tubes by piercing the saphaneous vein with a needle and subsequently into $0.5 \mathrm{~mL}$ microcentrifuge tubes. All blood samples were processed for plasma isolation by centrifugation at $1640 \mathrm{rpm}$ for $5 \mathrm{~min}$ at $4{ }^{\circ} \mathrm{C}$ within half an hour of collection. Finally serum profile of ALT, AST, ALP, creatinine, urea nitrogen was checked using respective kit as per manufacture's instruction.

Time course (predose and 0.25, 0.50, 1, 2, 4, 8, 12, 24h) change in mean plasma concentration of Z-DAN-11 after intravenous $(1 \mathrm{mg} / \mathrm{kg})$ and oral $(10 \mathrm{mg} / \mathrm{kg})$ administration of Z-DAN-11 was done by isolating plasma samples at each time point post oral and intravenous dose. An aliquot of $100 \mu \mathrm{L}$ blood sample were taken manually into heparinized capillary tubes by piercing the saphaneous vein with a needle and subsequently into $0.5 \mathrm{~mL}$ microcentrifuge tubes. All blood samples were processed for plasma isolation by centrifugation at $1640 \mathrm{rpm}$ for $5 \mathrm{~min}$ at $4{ }^{\circ} \mathrm{C}$ within half an hour of collection. Finally, samples were analyzed using Sciex 5500 Q-Trap LC-MS/MS and agilent 1290 series high performance liquid chromatograph. Kinetex Biphenyl (2.1 $30 \mathrm{~mm}, 5 \mu \mathrm{m}$ particle) column was used where the injection volume was $20 \mathrm{~mL} . \mathrm{H}_{2} \mathrm{O}$ containing $0.1 \%$ acetic acid or 90:20 MeCN: $\mathrm{H}_{2} \mathrm{O}$ containing $0.1 \%$ acetic acid were used differently as mobile phase.

\section{Statistical analysis}

All statistical analysis was performed by one-way ANOVA followed by Dunnett's test or Turkey test for comparing variable groups using GraphPad prism 5 software. In certain case Student's $t$-test was also performed. Values are expressed as mean \pm SEM for control and treated samples. The values were considered statistically significant as per $p$ values $\left(" p<0.05,{ }^{* * *} p<0.01\right.$, "**** $p<$ $0.001, \mathrm{~ns}=$ not significant).

\section{Acknowledgements}

We thank Dr. Gerd Ritter (Ludwig Institute of Cancer Research, USA) and Dr. James H. Finke (Cleveland Clinic Foundation, USA) for providing SK-RC-45 and NKE cells, respectively. We acknowledge Bose Institute for providing the instrumental facilities. This work was supported by funds provided by DST Fast Track Young Scientist Scheme (DST No: SR/FT/LS-053/2009 dated June 12,

2012), Govt. of India, and Bose Institute, Kolkata, India. PKP and BM

acknowlege CSIR, New Delhi for their financial support.

\section{Author details}

${ }^{1}$ Division of Molecular Medicine Bose Institute P1/12, C.I.T. Scheme VIIM Kolkata West Bengal 700054 India. ${ }^{2}$ The Bioinformatics Center, Bose Institute, Kolkata, West Bengal 700054, India. ${ }^{3}$ Saha Institute of Nuclear Physics, Kolkata, India

\section{Conflict of interest}

The authors declare that they have no conflict of interest.

\section{Publisher's note}

Springer Nature remains neutral with regard to jurisdictional claims in published maps and institutional affiliations.

Supplementary Information accompanies this paper at (https://doi.org/ 10.1038/s41419-018-0476-2).

Received: 23 September 2017 Revised: 15 January 2018 Accepted: 19 January 2018

Published online: 18 April 2018

\section{References}

1. Begg, A. C., Stewart, F. A. \& Vens, C. Strategies to improve radiotherapy with targeted drugs. Nat. Rev. Cancer 11, 239-253 (2011).

2. Chabner, B. A. \& Roberts, T. G. Chemotherapy and the war on cancer. Nat. Rev. Cancer 5, 65-72 (2005).

3. Chen, $\mathbf{X}$. et al. Protection of normal proliferating cells against chemotherapy by staurosporine-mediated, selective, and reversible G1 arrest. J. Natl Cancer Inst. 92, 1999-2008 (2000).

4. Cheok, C. F. Protecting normal cells from the cytotoxicity of chemotherapy. Cell Cycle 11, 2227 (2012).

5. Pandey, K. B. \& Rizvi, S. I. Plant polyphenols as dietary antioxidants in human health and disease. Oxid. Med. Cell Longev. 2, 270-278 (2009).

6. Safarzadeh, E., Sandoghchian Shotorbani, S. \& Baradaran, B. Herbal medicine as inducers of apoptosis in cancer treatment. Adv. Pharm. Bull. 4(Suppl 1), 421-427 (2014).

7. Zhou Y., et al. Natural polyphenols for prevention and treatment of cancer. Nutrients 8, E515 (2016).

8. Mukherjee, N. et al. Oxidative stress plays major role in mediating apoptosis in filarial nematode Setaria cervi in the presence of trans-stilbene derivatives. Free Radic. Biol. Med. 93, 130-144 (2016).

9. Lee, S. K. et al. Antibacterial and antifungal activity of pinosylvin, a constituent of pine. Fitoterapia 76, 258-260 (2005).

10. Lee, S. K. et al. Synthesis and evaluation of cytotoxicity of stilbene analogues. Arch. Pharm. Res. 26, 253-257 (2003).

11. Gosslau, A., Chen, M., Ho, C. T. \& Chen, K. Y. A methoxy derivative of resveratrol analogue selectively induced activation of the mitochondrial apoptotic pathway in transformed fibroblasts. Br. J. Cancer 92, 513-521 (2005).

12. Nam, K. A., Kim, S., Heo, Y. H. \& Lee, S. K. Resveratrol analog, 3,5,2',''-tetramethoxy-trans-stilbene, potentiates the inhibition of cell growth and induces apoptosis in human cancer cells. Arch. Pharm. Res. 24, 441-445 (2001).

13. Savio, M. et al. Resveratrol analogue $4,4^{\prime}$-dihydroxy-trans-stilbene potently inhibits cancer invasion and metastasis. Sci. Rep. 6, 19973 (2016).

14. Otto, T. \& Sicinski, P. Cell cycle proteins as promising targets in cancer therapy. Nat. Rev. Cancer 17, 93-115 (2017).

15. Goto, $\mathrm{H}$. et al. Identification of a novel phosphorylation site on histone $\mathrm{H3}$ coupled with mitotic chromosome condensation. J. Biol. Chem. 274, 25543-25549 (1999)

16. Mollinedo, F. \& Gajate, C. Microtubules, microtubule-interfering agents and apoptosis. Apoptosis 8, 413-450 (2003). 
17. Jordan, M. A. \& Wilson, L. Microtubules as a target for anticancer drugs. Nat. Rev. Cancer 4, 253-265 (2004).

18. Xiao, $\mathrm{H}$. et al. Insights into the mechanism of microtubule stabilization by Taxol. Proc. Natl Acad. Sci. USA 103, 10166-10173 (2006).

19. Vasquez, R. J., Howell, B., Yvon, A. M., Wadsworth, P. \& Cassimeris, L. Nanomolar concentrations of nocodazole alter microtubule dynamic instability in vivo and in vitro. Mol. Biol. Cell 8, 973-985 (1997).

20. Schneider, Y. et al. Resveratrol analog (Z)-3,5,4'-trimethoxystilbene is a potent anti-mitotic drug inhibiting tubulin polymerization. Int. J. Cancer 107, 189-196 (2003).

21. Labat-Moleur, F. et al. TUNEL apoptotic cell detection in tissue sections: critical evaluation and improvement. J. Histochem. Cytochem. 46, 327-334 (1998).

22. Wang, C. \& Youle, R. J. The role of mitochondria in apoptosis*. Annu. Rev. Genet. 43, 95-118 (2009).

23. Kumagai, A. \& Dunphy, W. G. Claspin, a novel protein required for the activation of Chk1 during a DNA replication checkpoint response in Xenopus egg extracts. Mol. Cell. 6, 839-849 (2000).

24. Karna, P. et al. A novel microtubule-modulating noscapinoid triggers apoptosis by inducing spindle multipolarity via centrosome amplification and declustering. Cell Death Differ. 18, 632-644 (2011).

25. Tseng, C. J. et al. Microtubule damaging agents induce apoptosis in HL 60 cells and G2/M cell cycle arrest in HT 29 cells. Toxicology 175, 123-142 (2002).

26. Rieder, C. L. \& Cole, R. Microtubule disassembly delays the G2-M transition in vertebrates. Curr. Biol. 10, 1067-1070 (2000).

27. Blajeski, A. L., Phan, V. A., Kottke, T. J. \& Kaufmann, S. H. G(1) and G(2) cell-cycle arrest following microtubule depolymerization in human breast cancer cells. J. Clin. Invest. 110, 91-99 (2002).

28. Shah, M. A. \& Schwartz, G. K. Cell cycle-mediated drug resistance: an emerging concept in cancer therapy. Clin. Cancer Res. 7, 2168-2181 (2001).

29. Kawabe, T. G2 checkpoint abrogators as anticancer drugs. Mol. Cancer Ther. 3, 513-519 (2004).

30. Tibbetts, R. S. et al. A role for ATR in the DNA damage-induced phosphorylation of p53. Genes Dev. 13, 152-157 (1999).

31. Loughery, J., Cox, M., Smith, L. M. \& Meek, D. W. Critical role for p53-serine 15 phosphorylation in stimulating transactivation at p53-responsive promoters. Nucleic Acids Res. 42, 7666-7680 (2014).

32. Feng, L., Hollstein, M. \& Xu, Y. Ser46 phosphorylation regulates p53-dependent apoptosis and replicative senescence. Cell Cycle 5, 2812-2819 (2006).

33. Oda, K. et al. p53AIP1, a potential mediator of p53-dependent apoptosis, and its regulation by Ser-46-phosphorylated p53. Cell 102, 849-862 (2000).

34. Ullrich, S. J. et al. Phosphorylation at Ser-15 and Ser-392 in mutant p53 molecules from human tumors is altered compared to wild-type p53. Proc. Natl Acad. Sci. USA 90, 5954-5958 (1993).
35. Twentyman, P. R. \& Luscombe, M. A study of some variables in a tetrazolium dye (MTT) based assay for cell growth and chemosensitivity. Br. J. Cancer 56, 279-285 (1987).

36. Mosmann, T. Rapid colorimetric assay for cellular growth and survival: application to proliferation and cytotoxicity assays. J. Immunol. Methods 65, 55-63 (1983).

37. Strober W. Typan blue exclusion test of cell viability. Curr Protoc Immunol. Appendix 3, Appendix3B (2001).

38. Harper, J. V. Synchronization of cell populations in G1/S and G2/M phases of the cell cycle. Methods Mol. Biol. 296, 157-166 (2005).

39. Chou, C. F. \& Omary, M. B. Mitotic arrest with anti-microtubule agents or okadaic acid is associated with increased glycoprotein terminal GlcNAc's. J. Cell Sci. 107(Pt 7), 1833-1843 (1994).

40. Ho, Y. S. et al. Griseofulvin potentiates antitumorigenesis effects of nocodazole through induction of apoptosis and G2/M cell cycle arrest in human colorectal cancer cells. Int. J. Cancer 91, 393-401 (2001).

41. Saeed, A. I. et al. TM4 microarray software suite. Methods Enzymol. 411, 134-193 (2006)

42. de Hoon, M. J., Imoto, S., Nolan, J. \& Miyano, S. Open source clustering software. Bioinformatics 20, 1453-1454 (2004).

43. Kundu, $M$. et al. Ganglioside GM2 mediates migration of tumor cells by interacting with integrin and modulating the downstream signaling pathway. Biochim. Biophys. Acta 1863(7 Pt A), 1472-1489 (2016).

44. Miller, E. Apoptosis measurement by annexin v staining. Methods Mol. Med. 88 191-202 (2004).

45. Parida, P. K. et al. Synthesis and evaluation of triazole linked glycosylated 18beta-glycyrrhetinic acid derivatives as anticancer agents. Bioorg. Med. Chem. Lett. 24, 3865-3868 (2014).

46. Wojtala, A. et al. Methods to monitor ROS production by fluorescence microscopy and fluorometry. Methods Enzymol. 542, 243-262 (2014).

47. Eruslanov, E. \& Kusmartsev, S. Identification of ROS using oxidized DCFDA and flow-cytometry. Methods Mol. Biol. 594, 57-72 (2010).

48. Dutta, A. et al. C-Glycosylated cinnamoylfuran derivatives as novel anti-cancer agents. RSC Adv. 7, 28853-28864 (2017)

49. Mahata, B. et al. GBM derived gangliosides induce T cell apoptosis through activation of the caspase cascade involving both the extrinsic and the intrinsic pathway. PLOS ONE 10, e0134425 (2015).

50. Franken, N. A. P., Rodermond, H. M., Stap, J., Haveman, J. \& van Bree, C. Clonogenic assay of cells in vitro. Nat. Protoc. 1, 2315-2319 (2006).

51. Noaman, E., Badr El-Din, N. K., Bibars, M. A., Abou Mossallam, A. A. \& Ghoneum M. Antioxidant potential by arabinoxylan rice bran, MGN-3/biobran, represents a mechanism for its oncostatic effect against murine solid Ehrlich carcinoma. Cancer Lett. 268, 348-359 (2008)

52. Fischer, A. H., Jacobson, K. A., Rose, J. \& Zeller, R. Hematoxylin and eosin staining of tissue and cell sections. CSH Protoc. 2008, pdbprot4986 (2008). 